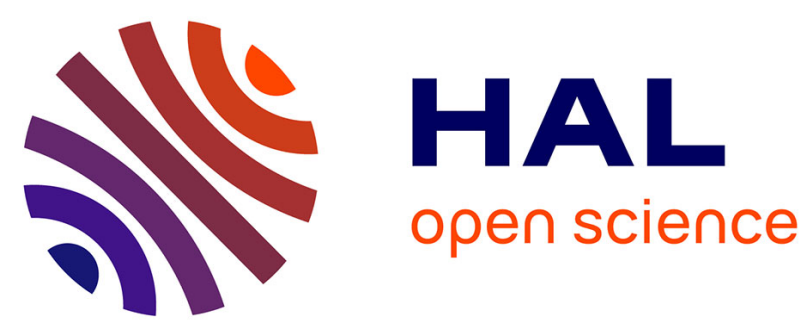

\title{
Partitioning evapotranspiration of a drip-irrigated wheat crop: Inter-comparing eddy covariance-, sap flow-, lysimeter- and FAO-based methods
}

\author{
Zoubair Rafi, Olivier Merlin, Valérie Le Dantec, Saïd Khabba, Patrick
} Mordelet, Salah Er-Raki, Abdelhakim Amazirh, Luis Enrique Olivera-Guerra, Bouchra Ait Hssaine, Vincent Simonneaux, et al.

\section{To cite this version:}

Zoubair Rafi, Olivier Merlin, Valérie Le Dantec, Saïd Khabba, Patrick Mordelet, et al.. Partitioning evapotranspiration of a drip-irrigated wheat crop: Inter-comparing eddy covariance-, sap flow-, lysimeter- and FAO-based methods. Agricultural and Forest Meteorology, 2019, 265, pp.310-326. 10.1016/j.agrformet.2018.11.031 . hal-03066927

\section{HAL Id: hal-03066927 https://hal.science/hal-03066927}

Submitted on 15 Dec 2020

HAL is a multi-disciplinary open access archive for the deposit and dissemination of scientific research documents, whether they are published or not. The documents may come from teaching and research institutions in France or abroad, or from public or private research centers.
L'archive ouverte pluridisciplinaire HAL, est destinée au dépôt et à la diffusion de documents scientifiques de niveau recherche, publiés ou non, émanant des établissements d'enseignement et de recherche français ou étrangers, des laboratoires publics ou privés. 


\title{
Partitioning evapotranspiration of a drip-irrigated wheat crop: inter- comparing eddy covariance-, sap flow-, lysimeter- and FAO-based methods
}

\author{
Zoubair Rafi ${ }^{1,2}$, Olivier Merlin ${ }^{1,2}$, Valérie Le Dantec ${ }^{2}$, Saïd Khabba ${ }^{1}$, Patrick Mordelet ${ }^{2}$, Salah \\ Er-Raki ${ }^{3}$, Abdelhakim Amazirh ${ }^{2,3}$, Luis Olivera-Guerra ${ }^{2}$, Bouchra Ait Hssaine ${ }^{1,2}$, Vincent \\ Simonneaux ${ }^{1,2}$, Jamal Ezzahar ${ }^{4}$, Francesc Ferrer ${ }^{5}$ \\ ${ }^{1}$ LMME, Faculté des Sciences Semlalia, Université Cadi Ayyad, Marrakech, Morocco \\ ${ }^{2}$ CESBIO, Université de Toulouse, IRD/UPS/CNRS/CNES, Toulouse, France \\ ${ }^{3}$ LP2M2E, Département de Physique Appliquée, Faculté des Sciences et Techniques, \\ Université Cadi Ayyad, Marrakech, Morocco \\ ${ }^{4}$ Equipe de Mathématique et Traitement de l'Information (MTI), Ecole Nationale des \\ Sciences Appliquées, Université Cadi Ayyad, Safi, Morocco \\ ${ }^{5}$ LabFerrer, Centro de asesoria Dr Ferrer, Cervera, Spain
}

\begin{abstract}
A precise estimate of the evapotranspiration (ET) partitioning is fundamental for determining the crop water needs and optimizing irrigation management. The plant transpiration $(T)$ is generally considered to be the most desirable component, while reducing the soil evaporation $(E)$ could be one of the most important water-saving actions in semi-arid agricultural regions. Given the lack of reference method to estimate the E/T partitioning of wheat crop, this study inter-compares four different methods based on eddy covariance, sap flow and lysimetry measurements and FAO modeling. The objectives are: i) to quantify the systematic and random uncertainty in $E$ and $T$ observations, ii) to evaluate the partitioning ratio (T/ET) at the daily/field scale and iii) to assess the performance of the FAO model over two drip irrigated wheat fields. Results indicate that despite the small surface sensed by minilysimeters, the partitioning ratio is evaluated more precisely (19\% relative error) with lysimetry than with the other systems (any combination of eddy covariance, lysimetry and sap flow measurements). Moreover, stem-scale T measurements from sap flow sensors are subject to representativeness issues at the field scale, and to systematic errors during water-stress and senescence periods. The lysimeter-derived partitioning ratio increases from about 0.50 to 0.85 during the growth stage and rapidly drops towards 0 during senescence. Its dynamics is found to be significantly correlated $(R>0.7)$ with the 5-cm soil moisture. By comparing FAO simulations with observations, it is found that the FAO method overestimates $T$ and underestimates E, while keeping satisfying ET estimates for drip irrigated wheat. This study suggests that different independent measurement techniques should be implemented to both quantify and reduce uncertainties in the T/ET ratio, and that accurate observations are still needed to improve the modeling of E/T components.
\end{abstract}


Keywords: Wheat, evaporation-transpiration, sap flow, lysimeter, eddy correlation, FAO-56.

\section{Introduction}

A precise estimate of evapotranspiration (ET) is fundamental for determining the crop water needs and subsequently for optimizing water management practices and irrigation regimes (Allen et al., 1998). ET includes soil evaporation (E), plant transpiration (T) and the evaporation of intercepted water. $\mathrm{E}$ and $\mathrm{T}$ processes in ecosystems are distinctly different. $\mathrm{T}$ is always used for the calculation of plant productivity, unlike $\mathrm{E}$ that does not contribute to the production. The partitioning of ET into gain and loss components for the ecosystem is generally defined by the term "water use efficiency" or more precisely "water productivity". In that sense, $\mathrm{T}$ is generally considered to be the most desirable component while $\mathrm{E}$ is undesirable (Agam et al., 2012; Van Halsema and Vincent, 2012). Reducing E could actually be one of the most important water-saving actions in semi-arid agricultural regions.

Given the growing concern about how to improve the water use efficiency of major irrigated crops, efforts have been made to estimate the T/ET (or the E/ET) ratio of wheat crops (Leuning et al., 1994; Denmead et al., 1996; Liu et al., 2002; Zhang et al., 2002; Kang et al., 2003; Balwinder-Singh et al., 2011; Zhang et al., 2011; Kool et al., 2014). The E/T partitioning of wheat crops is expected to change significantly across phenological stages (Allen et al., 1998). A brief overview of the studies documenting the E/T partitioning of wheat crops indicates that the T/ET ratio covers the 0-0.90 range (Kool et al., 2014).

One of the first estimates of this partition was derived by combining the $\mathrm{E}$ measured by micro-lysimeters underneath the wheat canopy and the ET estimated by the energy balance approach (Cooper el al., 1983; Leuning et al., 1994). The cumulated E to cumulated ET ratio over the agricultural season was estimated at $0.32-0.38$ for a wheat field in temperate climate (Leuning et al., 1994). Later, Demnead et al. (1996) combined micro-meteorological (ET) with micro-lysimetric (E) methods to estimate the E/ET ratio of a rainfed wheat field. The daily ratio varied from 0.87 to 0.10 for a leaf area index (LAI) ranging from 0.2 to $3.7 \mathrm{~m}^{2} \mathrm{~m}^{-2}$. Consistent results were obtained by Liu et al. (2002) and Kang et al. (2003) who combined micro-lysimeters (E) and large-scale weighing lysimeters (ET) set up in a sub-humid and semi-arid regions, respectively. The T/ET ratio ranged from 0 , at the sowing date, to $0.80-0.90$ at the growth peak and was found to be a function of LAI and surface soil moisture. More recently, Balwinder-Singh et al. (2011) combined micro-lysimeters (E) and the water balance approach (ET) and obtained an E/ET ratio ranging from 0.25 to 0.40 depending on the phenological stage, the study year, and the mulch treatment (minimum and maximum values corresponded to the mulched and non-mulched case, respectively). Zhang et al. (2011) and Aouade et al. (2016) combined isotopic (E/T ratio) and eddy covariance (ET) measurements over wheat fields in semi-arid climate. In the former study, the T/ET ratio was estimated at 0.83 and 0.60 on two dates separated by 11 days during the reproductive period. In the latter, the T/ET ratio was estimated at $0.69 \pm 0.08$ on three successive days with wet conditions (just 
after irrigation) and $0.80 \pm 0.04$ on two successive days with dry conditions during the vegetative period.

In the prospect of investigating the E/T partitioning for assessing the water use efficiency of wheat crops, continuous methods for measuring $\mathrm{E}$ or $\mathrm{T}$ separately are preferred rather than one-off or temporary measurements. Although being time consuming, micro-lysimeters are considered as being the most reliable method to measure E, as well as the T/ET ratio by using an independent measurement of ET (and by neglecting intercepted water). The technique of E measurements using micro-lysimeters is described in Boast and Robertson (1982) and Leuning et al. (1994). The technique consists in extracting a small (usually 10-15 cm in diameter) soil core, weighing manually the core, setting the core in situ underneath the canopy for typically 1 day, weighing the core again, and changing the soil in the lysimetric cylinder every 1 to 2 days to keep the conditions inside the lysimeter close to the outside field conditions (Boast and Robertson, 1982). The change in mass of the core is directly proportional to E, provided that the soil cores are replaced regularly (Daamen et al., 1993). Since the first manual and passive micro-lysimeters, efforts have been made to improve the system notably by using automated scales underneath the soil core (Grimmond et al., 1992; Ucles et al., 2013; Agam, 2014) and by artificially adding or extracting water from the cylinder bottom to mimic the real field conditions outside the micro-lysimeter (Brye et al., 1999).

Another potentially useful technique is the sap flow measurement. This technique is quite effective in estimating the $\mathrm{T}$ of orchards (Williams et al., 2004; Er-Raki et al., 2012; Cammalleri et al., 2013) and row crops (Heilman and Ham, 1990; Thompson et al., 1997; Agam et al., 2012). The advent of micro-sap flow sensors (Langensiepen et al., 2014; Miner et al., 2017) now allows for applying the methodology to plants with stems of 3-mm diameter. However, to the knowledge of the authors, none has been tested to specifically address the $\mathrm{E} / \mathrm{T}$ partitioning issue of wheat crops.

As an alternative to the above measurement methods, models can also be used to simulate $\mathrm{E}$ and $\mathrm{T}$ separately. The most common and probably the most operational modeling approach is the FAO dual crop coefficient model (FAO-2Kc, Allen, 2000). FAO-2Kc is extensively used to estimate ET, E and T fluxes, especially for orchards (e.g. Er-Raki et al., 2010; 2012), vineyards (e.g. Ferreira et al., 2012) and row crops (e.g. Ding et al., 2013). Although every surface model is subject to uncertainties due to errors in its input parameters and parameterizations, the point is that irrigation and meteorological forcing (via the atmospheric evaporative demand) are strong constraints on the crop water budget. In addition, in the case where irrigation volumes are precisely known at the crop field scale and meteorological data are monitored nearby, the water budget of the FAO-2Kc model is forced by known and spatially consistent input data, meaning that the output fluxes are simulated at the crop field scale unlike many E/T/ET measurement techniques representative of a much smaller area. In that sense, modeling tools like the FAO-2Kc are very useful as they provide independent estimates of water budget components at a (field/daily) scale relevant to water management. Nonetheless, few studies have addressed the E/T partitioning issue of field crops like wheat using the FAO-2Kc (Kool et al., 2014). 
In summary, various E/T methods (micro-meteorology, water balance, lysimetry, isotopy) have been implemented for wheat crops but three gaps are identified. First, each experimental study has generally used only two independent methods (for E, T or ET), so that the uncertainty in the estimated T/ET ratio cannot be evaluated. Second, the sap flow and FAO$2 \mathrm{Kc}$ methods have not been tested to assess the E/T partitioning of wheat crops. Third, continuous E/T/ET measurements across the agricultural season are rarely available, which makes it difficult to assign the dynamics changes of T/ET to environmental factors (phenological stage, LAI, surface soil moisture, etc.).

To fill the gap, this study inter-compares the E/T estimates of four different methods based on eddy covariance, sap flow and lysimetry measurements and FAO-2Kc modeling. The objectives are three-fold: 1) to propose a methodology for quantifying uncertainties in E/T/ET fluxes 2) to estimate at the daily scale the partitioning ratio (T/ET) of two drip irrigated wheat fields, and 3) to assess the performance of the FAO-2Kc model. To this end, two dripirrigated winter wheat crops in central Morocco are equipped with an eddy covariance tower (ET) and sap flow sensors (T). One field crop (reference wheat field) is irrigated according to the FAO crop water needs, while the other crop field (controlled stress field) undergoes several stress periods when irrigation is deliberately cut. Two autonomous and tensioncontrolled mini-lysimeters are installed in the controlled stress field, one measuring ET and the other measuring $\mathrm{E}$ alone.

\section{Materials and methods}

\subsection{Study area}

The study site $\left(31^{\circ} 25^{\prime} 36.4^{\prime \prime} \mathrm{N}, 8^{\circ} 39^{\prime} 05.9^{\prime \prime} \mathrm{W}\right)$ is located in the Haouz plain (centre of Morocco), about $70 \mathrm{~km}$ west of Marrakech city (Figure 1). The region is characterized by a semi-arid to arid climate with low precipitation $(<250 \mathrm{~mm} / \mathrm{year})$ against a strong reference evapotranspiration $\mathrm{ET}_{0}$ of about $1600 \mathrm{~mm} /$ year (Jarlan et al., 2015). In the case of wheat, historically, the most common irrigation method in the Marrakech region is flood irrigation. Recently, with the encouragement given by the Green Morocco Plan (PMV, 2013) to optimize the crop water use efficiency, a few farms have opted for the use of drip irrigation instead of flood irrigation.

In this study, conducted during 2016-2017 wheat season, we used two fields of winter wheat (variety Karim) of about 1.5 ha each (Figure 1). Wheat was sown on both plots on November $27^{\text {th }}, 2016$ by using an automatic seed drill with a distance of $15 \mathrm{~cm}$ between each sowing line. Fields are irrigated by drip method. The distance between irrigating tubes was $0.7 \mathrm{~m}$ and the distance between drippers was $0.4 \mathrm{~m}$. The flow rate of each dripper is $21 /$ hour, which is equivalent to $7.14 \mathrm{~mm} /$ hour. During this experiment, the mean duration of irrigation was 1 hour 45 minutes equivalent to $12.53 \mathrm{~mm}$. 
157 Both fields had the same technical itineraries except that one field (reference field) had been 158 irrigated according to the FAO crop water requirements while the other field (controlled stress 159 field) had been stressed voluntarily during three periods. Each field was equipped with an 160 eddy covariance station (installed on November $24^{\text {th }}, 2016$ ) and sap flow sensors (installed on 161 March $8^{\text {th }}, 2017$ ). Also, the surface net radiation Rn (which is the net effect of incoming and 162 outgoing long and short-wave radiation) was measured by using CNR1 sensor, the soil heat 163 flux density was measured at $5 \mathrm{~cm}$ depth by using heat flux plates (HFT3-L), and the soil 164 moisture content at different depths by using TDR sensors. In addition, the controlled stress 165 field was equipped with a lysimeter station (installed on November $22^{\text {nd }}, 2016$ ). Irrigation 166 volumes are precisely collected at a single valve by a flowmeter. Moreover, an automatic 167 weather station was set up, over an alfalfa near the studied wheat fields, to provide continuous measurements of meteorological forcing and $\mathrm{ET}_{0}$ estimates. 

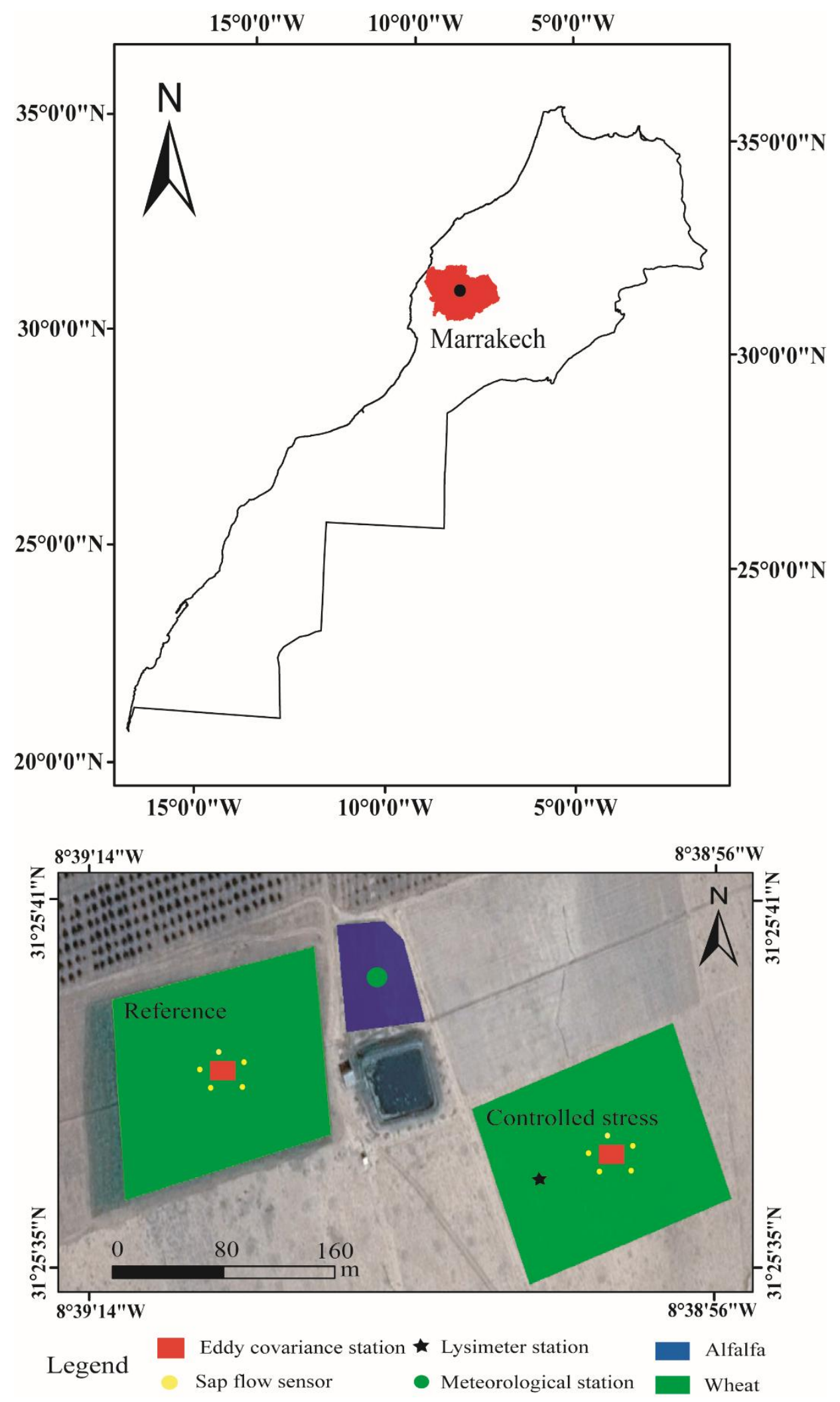

Figure 1: Location of the Tensift basin in Morocco and set up of the experiment over the two (reference and controlled stress) drip-irrigated wheat fields. 
The EC system was installed at the centre of each wheat field at a height of $2.58 \mathrm{~m}$. The choice of the installation height resulted in a compromise between two constraints: 1) sampling within the field for a range of wind directions and 2) measuring at least $1.7 \mathrm{~m}$ above the top of the canopy. The EC consists of a 3D sonic anemometer (CSAT3, Campbell Scientific Ltd.) that measures the three components of wind speed, and a krypton $\mathrm{KH} 2 \mathrm{O}$ hygrometer that measures the rapid fluctuations of atmospheric water vapor. Raw data sampled at a rate of $20 \mathrm{~Hz}$ are used to calculate sensible $\left(\mathrm{H}_{\mathrm{EC}}\right)$ and latent heat $\left(\mathrm{LE}_{\mathrm{EC}}\right)$ fluxes offline using the EC processing software 'ECpack' (Van Dijk et al. 2004), developed by the Meteorology and Air Quality Group, Wageningen University. The correlation between observed available energy ( - net radiation minus ground heat flux) and the sum of turbulent fluxes $\left(\mathrm{H}_{\mathrm{EC}}+\mathrm{LE}_{\mathrm{EC}}\right)$ is very significant for both controlled stress $\left(\mathrm{R}^{2}=0.88\right)$ and reference $\left(\mathrm{R}^{2}=0.93\right)$ field. However, the slope of the linear regression is 0.55 and 0.44 , respectively, which result in a systematic underestimation of turbulent fluxes by EC system. Therefore, a correction of $\mathrm{H}_{\mathrm{EC}}$ and $\mathrm{LE}_{\mathrm{EC}}$ is applied while preserving the available energy using Bowen's ratio (Twine et al., 2000). For a mean wind speed of $1.95 \mathrm{~m} / \mathrm{s}$ and a direction of 58 degrees, the fetch corresponding to the EC equipment measurements is $50 \mathrm{~m}$ long and $32.5 \mathrm{~m}$ wide and this for a total contribution of $95 \%$.

The difference obtained between $(\mathrm{Rn}-\mathrm{G})$ and uncorrected $(\mathrm{Hec}+\mathrm{LEec})$ is significant. Such difference is explained by the combination of several factors. First, the underestimation of fluxes measured by the Eddy covariance system can be due to the attenuation of turbulent signals at sufficiently low or high frequencies (Moore, 1986). Second, the source area of the sensors that measure the available energy (net radiation and conductive flux in the ground) is very small compared to that of the Eddy covariance system which can be changed rapidly depending on wind speed and direction and surface conditions. Third, the heat storage above the soil heat flux plate measurements was not considered. The rationale is that this study focuses on daily fluxes and that the heat storage at the daily time scale is zero. In addition, Scott et al. (2003) found that the energy stored in biomass represents about 5\% of the available energy, which could explain part of the non-closure of the energy balance.

The 30-min LE data is hence corrected at each time step, and an average is applied over 24 hours to estimate the daily LE. Finally, daily LE is converted from $\mathrm{W} / \mathrm{m}^{2}$ to $\mathrm{mm} / \mathrm{day}$ by multiplying it by a factor of 0.035 (Table 3, FAO-56, Allen et al., 1998).

\subsection{Lysimeter (Lys) station:}

A Smart Field Lysimeter (SFL) station was installed in the controlled stress field. The SFL was connected to two mini-Lys (30 cm in diameter): one $30 \mathrm{~cm}$ depth Lys and one $90 \mathrm{~cm}$ depth Lys. As this study focuses on the E/T partitioning, the two Lys were prepared to measure separately the E and ET terms (see appendix A). The 30-cm deep Lys was dedicated to measure $\mathrm{E}\left(\mathrm{E}_{\mathrm{Lys}}\right)$, while the $90-\mathrm{cm}$ deep Lys was dedicated to measure ET $\left(\mathrm{ET}_{\mathrm{Lys}}\right)$. For simplicity the E measured by the 30-cm Lys and the ET measured by the 90-cm Lys are both referred to ET measurements below (with T equal to 0 in the former case). 
Both Lys were sown (see Figure 2.d) on November $27^{\text {th }} 2016$, respecting the density (30 grams $/ \mathrm{m}^{2}$ ) of seedlings that were applied to the entire field by the automatic seed drill (Figure 2a). Special attention was paid to the irrigation of both Lys. Due to representativeness issues, the irrigation flow rate at the Lys surface had to be reduced to approximately one fourth of the original dripper flow rate $(2$ /hour). This value comes from a simple computation of the surface area fed by one dripper in field conditions: drip pipes are separated by $70 \mathrm{~cm}$ and drippers are set every $40 \mathrm{~cm}$ along each pipe, so that the elementary surface for each dripper is $0.28 \mathrm{~m}^{2}$, which is approximately 4 times the surface area $\left(0.07 \mathrm{~m}^{2}\right)$ of the SFL Lys. The irrigation system of Lys consisted of 1) an autoregulated dripper (connected to the nearest drip pipe of each Lys) designed to keep a flow of 2 1/hour and 2) a distribution network (connected to the autoregulated dripper) with 4 exits, designed to distribute equally the inflow, that is to obtain a stable outflow of $0.5 \mathrm{l} /$ hour at the Lys level (Figure 2c). A flow rate of $0.51 /$ hour ensures that the Lys top boundary conditions are representative of the whole crop field (Figure $2 \mathrm{~d})$.

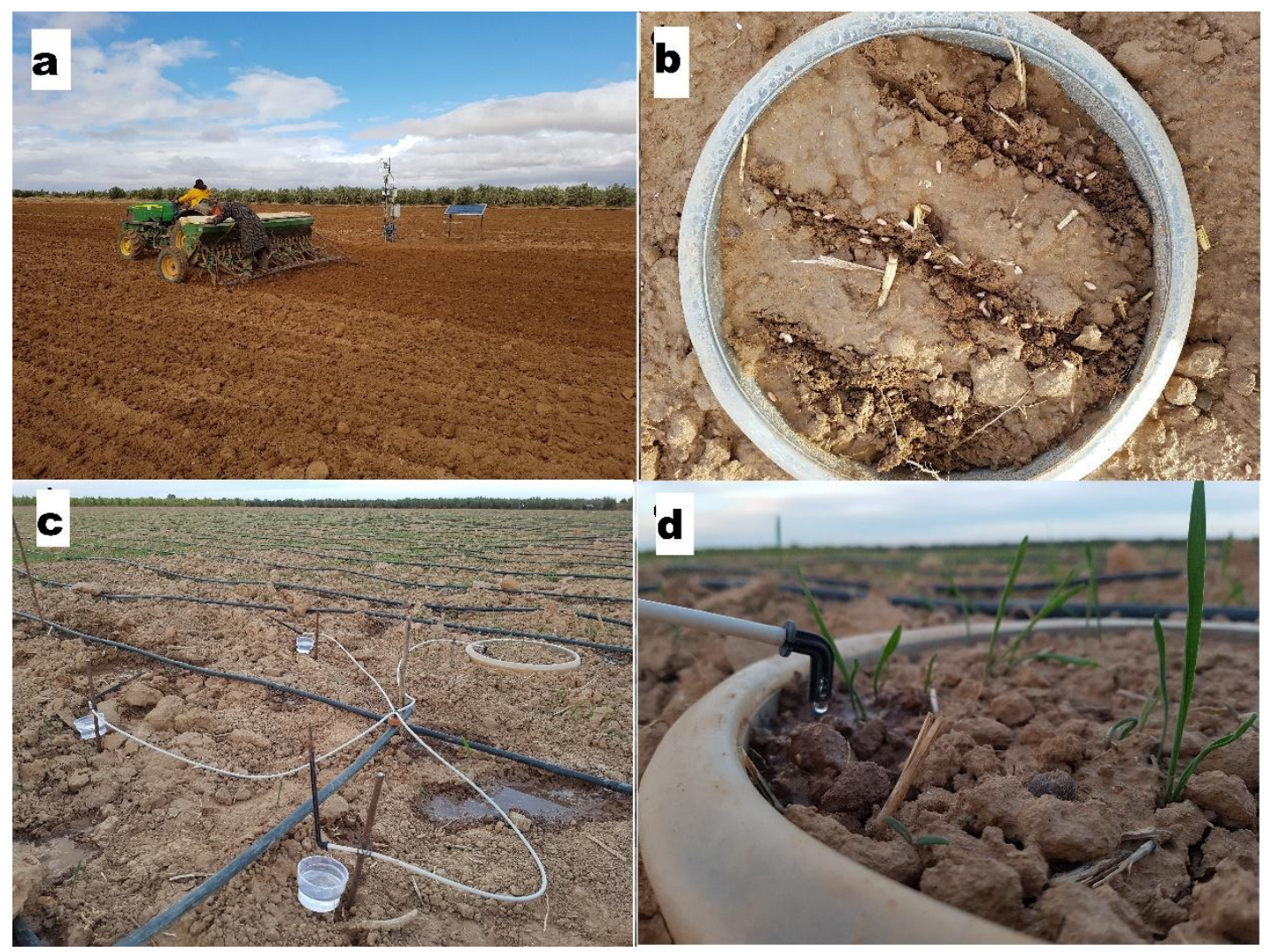

Figure 2: a) Automatic seed drill used to sow wheat. b) Surface of the SFL Lys sowed by wheat seeds. c) The primary dripper flow ( 2 1/hour) is divided by 4 to make the Lys upper boundary condition representative of the whole crop field, and the flow rate at Lys level $(0.5$ 1/hour) is checked at the beginning of the experiment. $d)$ The secondary dripper $(0.51 /$ hour $)$ feeding the Lys.

Both Lys measured ET (including E and T components) until March $1^{\text {st }}, 2017$. On March $2^{\text {nd }}$ 2017, the herbicide "roundup" was applied to the 30-cm deep Lys. Roundup is a systemic 
experimental strategy was undertaken 1) to remove the T component over the 30-cm deep Lys and 2) to reproduce as much as possible the shielding effects of wheat canopy on the E. Hence, Lys-derived E and ET are available from March the $3^{\text {rd }} 2017$ until the end of the season.

\subsection{Sap flow (SF):}

The stem heat balance (SHB) method for measuring sap flux relies on i) the addition of a given thermal energy at a point of the stem, trunk or branch of a plant, and ii) the measurement of the dissipation of this energy by convection via the SF of the stem. The SF is strongly related to $\mathrm{T}$, which accounts for as much as $99 \%$ of the soil water uptake. The SF measurement can thus be considered as equal to the plant $\mathrm{T}$ (Gerdes et al., 1994).

During our experiment, five Dynagage SF sensors (Dynamax Inc, 2005) were used on each (controlled stress and reference) field. The sensors were moved from one stem to another every ten days. The objective was both to avoid damaging the monitored stems and to cover a range of stem diameters. To upscale single-stem measurements to the field scale, the diameter of each monitored stem as well as the actual distribution of diameter classes per $\mathrm{m}^{2}$ was taken into account. A stem density campaign (March 28 $8^{\text {th }}$ 2017) was carried out on both experimental fields. An average density of 416 and $504 \mathrm{stems} / \mathrm{m}^{2}$ was found on the controlled stress and reference field, respectively. Five variability ranges in stem diameter were extracted ([2.2;3.1], [3.1;3.7], [3.7;4.3], [4.3;4.8], [4.8;5.3] in $\mathrm{mm}$ ) with a percentage contribution for each interval of $(6.8,34.3,20.5,27.5,10.9 \%$ respectively) for the controlled stress plot. For the reference parcel, the five diameter intervals were ([2;3.4], [3.4;4.1], [4.1;4.8], [4.8;5.3], $[5.3 ; 6.3] \mathrm{mm})$ with a percentage contribution for each interval of $(26.4,23.6,37.5,4.2,8.3 \%$ respectively). The mean (and standard deviation) of the diameter was estimated at $4.11(0.68)$ $\mathrm{mm}$ and $4.05(0.78) \mathrm{mm}$ for the controlled stress and reference fields, respectively.

Based on the stem variability ranges, the hourly field-scale SF-derived T is estimated as:

$$
T_{S F}=\sum_{i=1}^{5} P_{c}(i) * T_{S F}(i)
$$

where $\mathrm{P}_{c}(\mathrm{i})$ is the percentage of the diameter range $\mathrm{i}$ and $\mathrm{T}_{\mathrm{SF}}(\mathrm{i})$ the $\mathrm{T}$ measured by a SF sensor installed around a stem with diameter falling within the diameter range $\mathrm{i}$ (see appendix $\mathrm{B}$ ). Daily SF-derived T estimates are obtained by summing the hourly scaled SF-derived T. Note that the data for days when more than one-third of SF measurements are missing (or invalid) are removed (25\% of the data). Based on the same approach, the variability in $\mathrm{T}$ measurements can be assessed by computing the weighted standard deviation of individual $\mathrm{T}$ estimates:

$$
\sigma_{T_{S F}}=\sqrt{\frac{1}{4} \sum_{i=1}^{5} P_{c}(i) *\left(T_{S F}(i)-T_{S F}\right)^{2}}
$$

\subsection{Ancillary data}


Other auxiliary measurements were carried out during the experiment. LAI measurements were made on a regular basis using hemispheric photos combined with biomass measurements. Cubic interpolation was used to obtain a daily estimate of LAI over the entire season. In addition, the Normalized Difference Vegetation Index (NDVI) was measured by a SKYE reflectometer installed over the controlled stress field. For the reference field, given that no NDVI sensor was available, NDVI was derived by combining the photo-derived LAI and a NDVI-LAI relationship developed for wheat in Er-Raki et al. (2007). The fractional vegetation cover ( $\mathrm{fc}$ ) was derived by normalizing the NDVI by its minimum and maximum values obtained during the season. Also, in the rest of the paper we will use the normalized soil surface moisture (NSSM), which is derived from the surface $(5-\mathrm{cm})$ soil moisture (SSM) normalized by its minimum and maximum values observed during the field experiment.

\subsection{FAO dual crop coefficient (FAO-2Kc) approach}

In FAO-2Kc, the crop ET is expressed as:

$$
E T_{c}=\left(K_{c b}+K_{e}\right) * E T_{0}
$$

where $\mathrm{ET}_{\mathrm{c}}$ is the FAO-simulated potential $\mathrm{ET}, \mathrm{K}_{\mathrm{e}} * \mathrm{ET}_{0}$ the $\mathrm{E}$ component and $\mathrm{K}_{\mathrm{cb}}$ the basal crop coefficient. The coefficient $\left(\mathrm{K}_{\mathrm{cb}}+\mathrm{K}_{\mathrm{e}}\right)$ represents the ratio of $\mathrm{ET}_{\mathrm{FAO}}$ to $\mathrm{ET}_{0}$ under wellwatered conditions (no vegetation stress). For actual estimates of the real crop ET ( $\left.\mathrm{ET}_{\mathrm{FAO}}\right)$, $\mathrm{K}_{\mathrm{cb}}$ is adjusted by the water stress coefficient $\mathrm{K}_{\mathrm{s}}$ :

$$
E T_{F A O}=\left(K_{c b} \cdot K_{S}+K_{e}\right) * E T_{0}
$$

where $\mathrm{ET}_{\mathrm{FAO}}$ is the FAO-simulated daily $\mathrm{ET}, \mathrm{K}_{\mathrm{s}}<1$ for conditions when the soil water is a limiting factor, and $\mathrm{K}_{\mathrm{s}}=1$ when the root-zone soil water is easily available to $\mathrm{T}$. Therefore, all three parameters $\mathrm{K}_{\mathrm{cb}}, \mathrm{K}_{\mathrm{e}}$ and $\mathrm{K}_{\mathrm{s}}$ are needed to estimate ET. The main equations of the FAO$2 \mathrm{Kc}$ approach are reminded in Appendix $\mathrm{C}$.

The need for local calibration of the FAO model has been stressed by a number of studies (ErRaki et al., 2007; 2011; Le Page et al., 2014). Herein, FAO-2Kc is calibrated by adjusting its ten main parameters:

- the length ( $\mathrm{L}$, number of days after sowing) of the initial $\left(\mathrm{L}_{\mathrm{ini}}\right)$, development $\left(\mathrm{L}_{\mathrm{dev}}\right)$, midseason $\left(\mathrm{L}_{\mathrm{mid}}\right)$ and late $\left(\mathrm{L}_{\mathrm{end}}\right)$ phenological phase,

- the basal crop coefficient ( $\mathrm{K}_{\mathrm{cb}}$, unitless) that is interpolated at the daily scale between the start and end value $\left(\mathrm{K}_{\mathrm{cb} \text {,ini }}, \mathrm{K}_{\mathrm{cb} \text {,mid }}, \mathrm{K}_{\mathrm{cb} \text {,end }}\right)$ of each phenological phase,

- the depth (Ze, mm) of surface soil layer subjected to drying by evaporation,

- the maximum depth of water (REW, $\mathrm{mm}$ ) that can be evaporated without restriction from the soil surface layer, and

- the maximum rooting depth $\left(\mathrm{Z}_{\mathrm{r}, \max }, \mathrm{m}\right)$. 
Each parameter is adjusted separately by setting all the other parameters to their default (FAO) value and by maximizing the determination coefficient i) between modeled and ECderived ET estimates and ii) between modeled and SF-derived T estimates. Interestingly enough, the maximum of correlation for $\mathrm{ET}$ and $\mathrm{T}$ estimates was found to occur simultaneously for the same set of parameter values.

Calibrated parameters are listed in Table 1. They are rather close for both experimental fields, but they significantly differ from the FAO default values, especially for the duration of phenological phases. Note however that the calibrated $\mathrm{L}_{\mathrm{ini}}, \mathrm{L}_{\mathrm{dev}}$ and $\mathrm{L}_{\mathrm{mid}}$ are in accordance with the NDVI measurements carried out on the site. Also, the site-specific $Z_{e}$ and $Z_{r, \max }$ values may be due to the soil type, which is characterized by a clay and sand fraction of $32.5 \%$ and $37.5 \%$, respectively. Calibrated values of $Z_{r, \max }$ and $K_{c b \text {,mid }}$ are $0.55 \mathrm{~m}$ and 0.95 respectively, consistent with other fields in the region (Er-Raki et al., 2007, Belaqziz et al., 2013).

Table 1: Default (FAO) and site-specific FAO-2Kc parameters for controlled stress and reference fields separately.

\begin{tabular}{|l|l|l|l|}
\hline Parameter & FAO & Controlled stress & Reference \\
\hline $\mathrm{K}_{\mathrm{cb}, \text { ini }}(-)$ & $0.15^{*}$ & $0.30^{*}$ & $0.30^{*}$ \\
\hline $\mathrm{K}_{\mathrm{cb} \text {,mid }}(-)$ & 0.90 & 0.95 & 0.95 \\
\hline $\mathrm{K}_{\mathrm{cb}, \text { late }}(-)$ & 0.23 & 0.15 & 0.15 \\
\hline $\mathrm{L}_{\text {ini }}$ & 31 & 31 & 31 \\
\hline $\mathrm{L}_{\text {dev }}$ & 34 & 34 & 40 \\
\hline $\mathrm{L}_{\text {mid }}$ & 59 & 65 & 66 \\
\hline $\mathrm{L}_{\text {late }}$ & 46 & 40 & 33 \\
\hline $\mathrm{Z}_{\mathrm{e}}(\mathrm{m})$ & 0.10 & 0.10 & 0.10 \\
\hline REW $(\mathrm{mm})$ & 9 & 8 & 8 \\
\hline $\mathrm{Z}_{\mathrm{r} \text {,max }}(\mathrm{m})$ & 0.90 & 0.55 & 0.55 \\
\hline
\end{tabular}

$* \mathrm{~K}_{\mathrm{cb} \text {,ini }}$ is set to zero for NDVI 0.14 (bare soil) and a linear interpolation of $\mathrm{K}_{\mathrm{cb} \text {,ini }}$ is performed from the plant emergence until the last day of the initial phase where $\mathrm{K}_{\mathrm{cb} \text {,ini }}$ is set to 0.15 (default) or 0.30 (value obtained after calibration).

The calibration approach is evaluated by comparing error statistics before and after calibration. For the controlled stress field, on one hand the coefficient of determination $\left(\mathrm{R}^{2}\right)$ between the simulated and observed ET flux increases from 0.70 to 0.75 . The root mean square difference (RMSD) slightly varies from 0.72 to $0.75 \mathrm{~mm}$ /day and the mean difference (MD) from -0.03 to $-0.05 \mathrm{~mm} /$ day. On the other hand, the $\mathrm{R}^{2}$ increases significantly from 0.48 
to 0.63 between the simulated and measured T, while the RMSD (MD) slightly varies from 0.62 to $0.66 \mathrm{~mm} /$ day (from -0.89 to $-0.99 \mathrm{~mm} /$ day). For the reference field, the $\mathrm{R}^{2}$ between simulated and measured fluxes increases from 0.25 to 0.38 and from 0.78 to 0.81 for the $\mathrm{T}$ and ET estimates, respectively. The RMSD (MD) slightly changes from 0.64 to $0.83 \mathrm{~mm} /$ day (from -0.68 to $-1.15 \mathrm{~mm} /$ day) and from 0.66 to $0.83 \mathrm{~mm} /$ day (from 0.36 to $0.27 \mathrm{~mm} /$ day) for the $\mathrm{T}$ and ET case, respectively. Overall, calibration results are fully consistent with the local calibration undertaken by Er-Raki et al. (2007) over 3 distinct wheat crop fields over the same study area yielding a RMSD with EC-derived ET of 0.45, 0.99, $0.75 \mathrm{~mm} /$ day.

\subsection{Uncertainty analysis}

The strategy to inter-compare EC, Lys, SF and FAO flux estimates and to assess uncertainties in E/T/ET estimates is presented. Given that is it difficult to rely on any measurement or modeling approach as an absolute reference for estimating the E/T partitioning, a new approach is proposed to estimate the systematic and random uncertainties in FAO, EC, Lys and SF methods. Herein, systematic uncertainty is defined as a persistent error that lasts for one week or more, while random uncertainty is defined as a relative error (error in the flux relative to the flux amplitude) that remains at the daily scale after removing systematic uncertainty.

For the systematic uncertainty analysis, as FAO-2Kc provides E, T and ET estimates, the FAO model is used for practical reasons as a common denominator in the inter-comparison of all approaches. The point is that the FAO model cannot be used as a reference for evaluating measurements. Therefore, any persistent difference between methods may be interpreted as a systematic error in the FAO and/or the measurement method.

For the random uncertainty analysis, the FAO model is also used as a common denominator in the inter-comparison of measurement methods but, since the FAO is generally more uncertain than observations, any systematic difference between FAO and measurements is removed at the 7-day scale. Specifically, the flux modeled by the FAO approach is corrected by making the difference between both 7-day smoothed estimates:

$F_{\mathrm{FAO}, \mathrm{Obs}}=F_{\mathrm{FAO}}-F_{F A O, \text { Roll }}+F_{O b s, \text { Roll }}$

with $\mathrm{F}$ being the estimated (either ET, $\mathrm{T}$ or E) flux, $\mathrm{F}_{\mathrm{FAO}}$ the FAO-simulated flux, $\mathrm{F}_{\mathrm{FAO}, \mathrm{Obs}}$ the flux simulated by FAO model and corrected by the 7-day smoothed observed flux, $\mathrm{F}_{\mathrm{FAO}, \mathrm{Roll}}$ the 7-day smoothed FAO-simulated flux and $\mathrm{F}_{\mathrm{Obs} \text {,Roll }}$ the 7-day smoothed observed flux. Note that the observed flux is derived by either EC and Lys or SF data or any combination between them. Equation (5) means that only the (short-term) day-to-day variations of the FAOsimulated fluxes are kept for the inter-comparison of the random uncertainty in measurement methods. The risk is thus limited as 1) systematic errors in FAO model have been removed and 2) the FAO model is very well constrained at the daily scale by the well monitored irrigation and $\mathrm{ET}_{0}$ input data.

Finally, an estimate of the random uncertainty in the T/ET ratio, noted $\delta(T / E T) /(\overline{T / E T})$, can be estimated by taking the derivative of the logarithm of each term: 
$368 \quad \frac{\delta(T / E T)}{\overline{T / E T}}=\frac{\delta T}{\bar{T}}+\frac{\delta E T}{\overline{E T}}$

369 with $\delta T$ being the standard deviation between corrected FAO-simulated and measured T, $\bar{T}$

370 the mean measured T during the study period, $\delta E T$ the standard deviation between corrected

371 FAO-simulated and measured ET and $\overline{E T}$ the mean measured ET during the study period.

372 Note that Equation (6) is valid if variables are exempt from systematic uncertainties.

\section{Results and discussion}

374

375

376

377

378

379

380

381

382

383

384

385

386

387

388

389

390

391

392

393

394

All methods (FAO-2Kc, EC, Lys, SF) are inter-compared to evaluate both systematic and random uncertainties in E, T and ET estimates over both (controlled stress and reference) crop fields. The dynamics of a best estimator of the partitioning ratio is then analyzed at the daily to seasonal time scales in response to several environmental and biophysical factors such as LAI, NSSM and vapor pressure deficit (VPD).

3.1 Systematic differences between ET, T and E methods

\subsubsection{Evapotranspiration}

Figure 3 shows the daily evolution of EC-derived and Lys-derived ET along with the amount of precipitation and irrigation for the controlled stress and reference fields separately. One can see the general coherence between FAO, EC and Lys estimates across all phenological phases. When comparing both experimental fields, Figure 3 shows that the ET measured by EC is significantly larger for the reference than for the controlled stress field. This is expected because the reference field did not experience water stress as previously mentioned. In particular, the daily ET reaches $7.1 \mathrm{~mm}$ at reference field against a maximum value of $5.4 \mathrm{~mm}$ on the same date at controlled stress field. This effect is notably visible between Day Of Year (DOY) 65 and DOY 85, when the ET at controlled stress field is $1 \mathrm{~mm}$ to $3 \mathrm{~mm}$ less than that at reference field, due to the water supply shortage over the controlled stress field.

When comparing ET methods over the controlled stressed field (Figure 3a), slight differences between EC- and Lys-derived ET could be attributed to a lack of representativeness of the conditions inside the Lys. However, representativeness issues are limited by the regulation of the soil water tension at the SFL Lys bottom. 

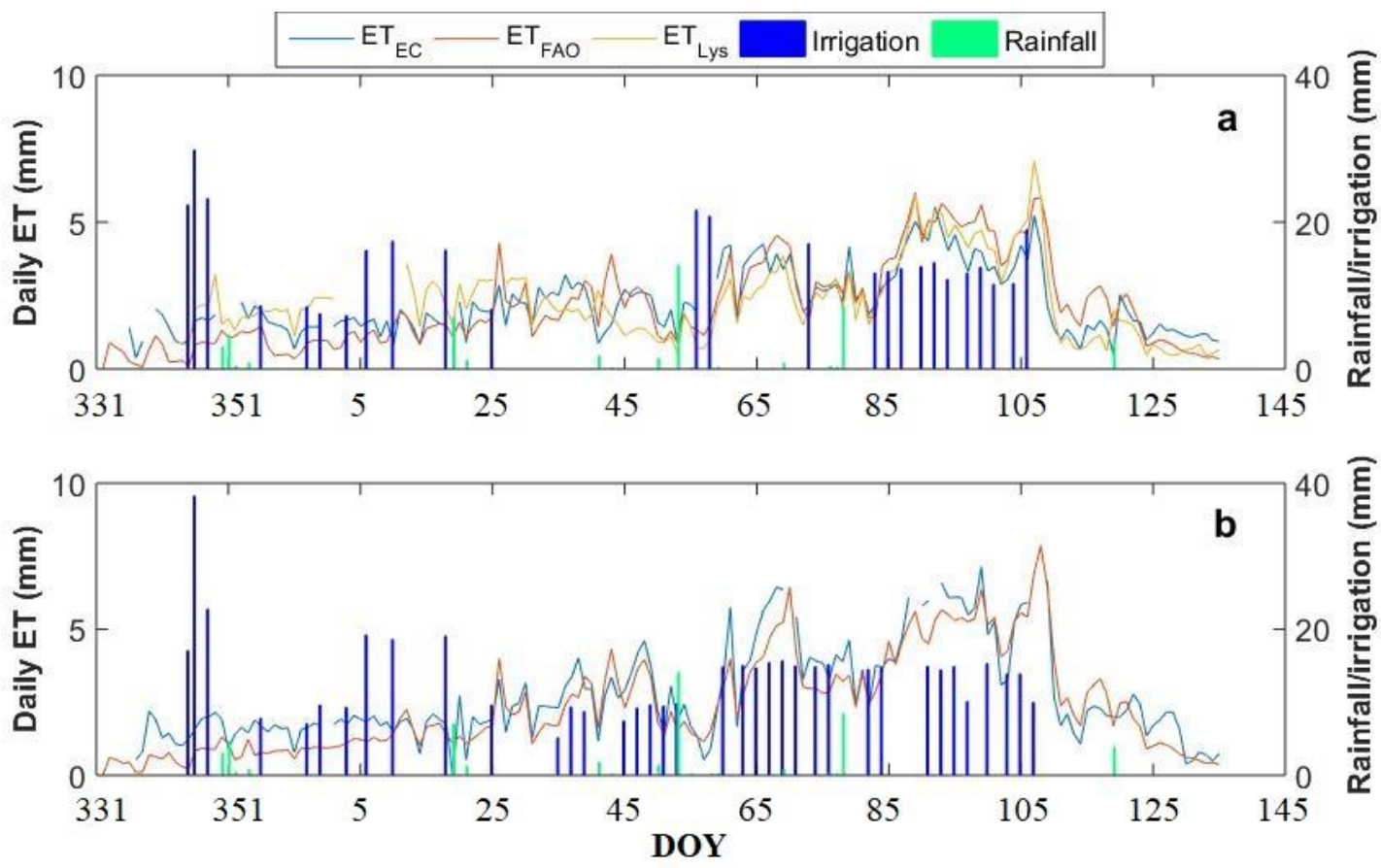

Figure 3: Time series of EC-derived, Lys-derived and FAO-simulated daily ET at the controlled stress (a) and reference (b) field.

In fact, despite the huge discrepancy existing between the spatial extent of both ET techniques, EC- and Lys-derived ET estimates are deemed consistent as differences between those independent measurements remain relatively low (with an overall RMSD of 0.73 $\mathrm{mm}$ /day). The EC-derived ET matches much better the Lysimeter-derived ET with Bowen correction than without correction (with an overall RMSD of $1.14 \mathrm{~mm} / \mathrm{day}$ ).

When comparing the FAO model with the other two ET methods (EC and Lys) in Figure 4 and 5, it appears that the modeled flux is systematically lower than both the Lys- and ECderived ET during the initial stage. Associated statistical results are listed in Table 2. The slope of the initial period $\left(\mathrm{a}_{\mathrm{ini}}=0.40\right)$ is much lower than that of both development and midseason $\left(\mathrm{a}_{\mathrm{dev}+\mathrm{mid}}=0.82\right)$ and late $\left(\mathrm{a}_{\mathrm{late}}=0.98\right)$ periods. The systematic underestimation of the FAO model during the initial stage is probably due to an underestimation of the E flux. Such an assumption will be further assessed below by investigating independent $\mathrm{T}$ and $\mathrm{E}$ estimates. 

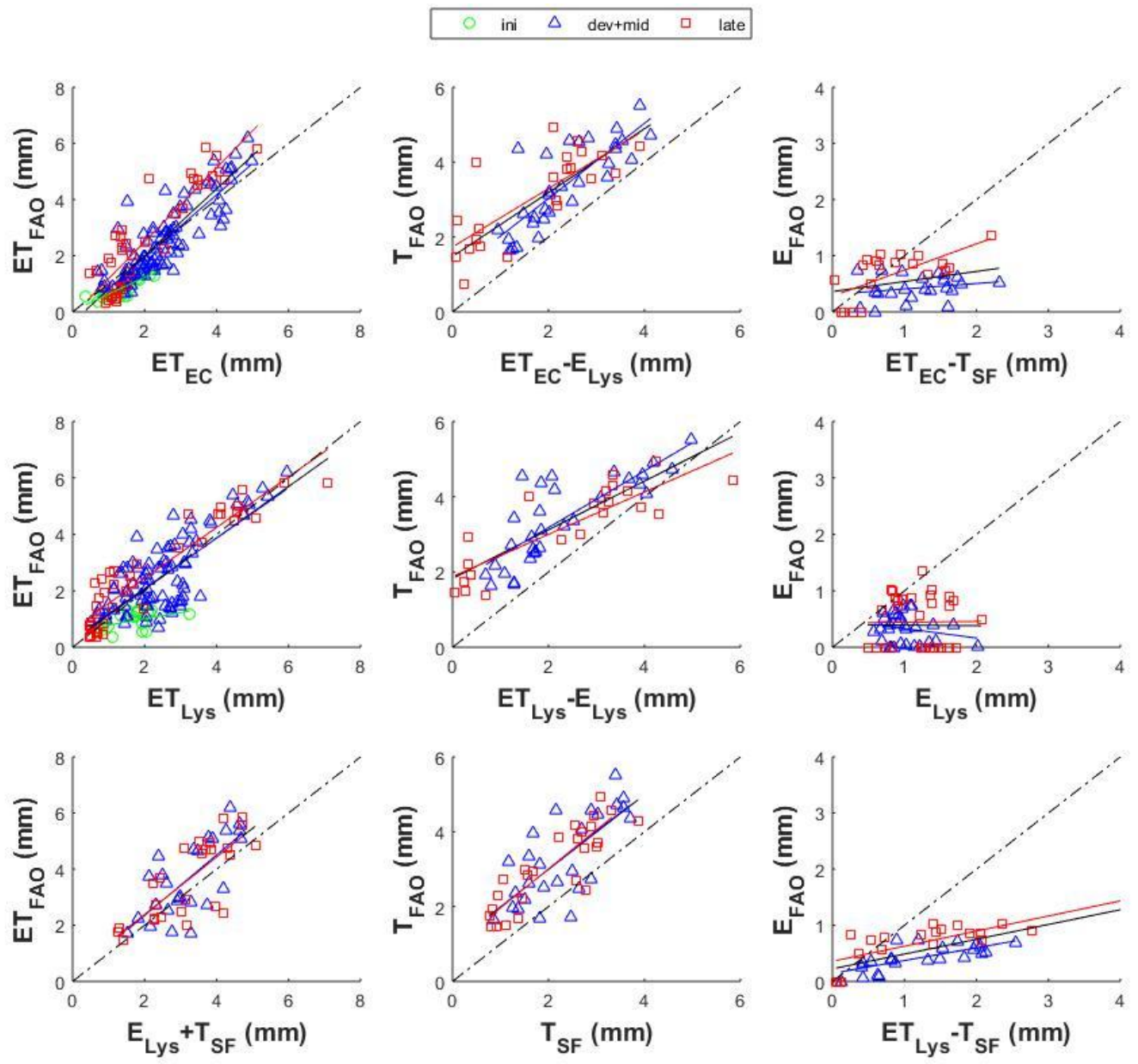

411 Figure 4: Scatterplot of FAO-simulated versus measured ET/T/E fluxes over the controlled stress field. 

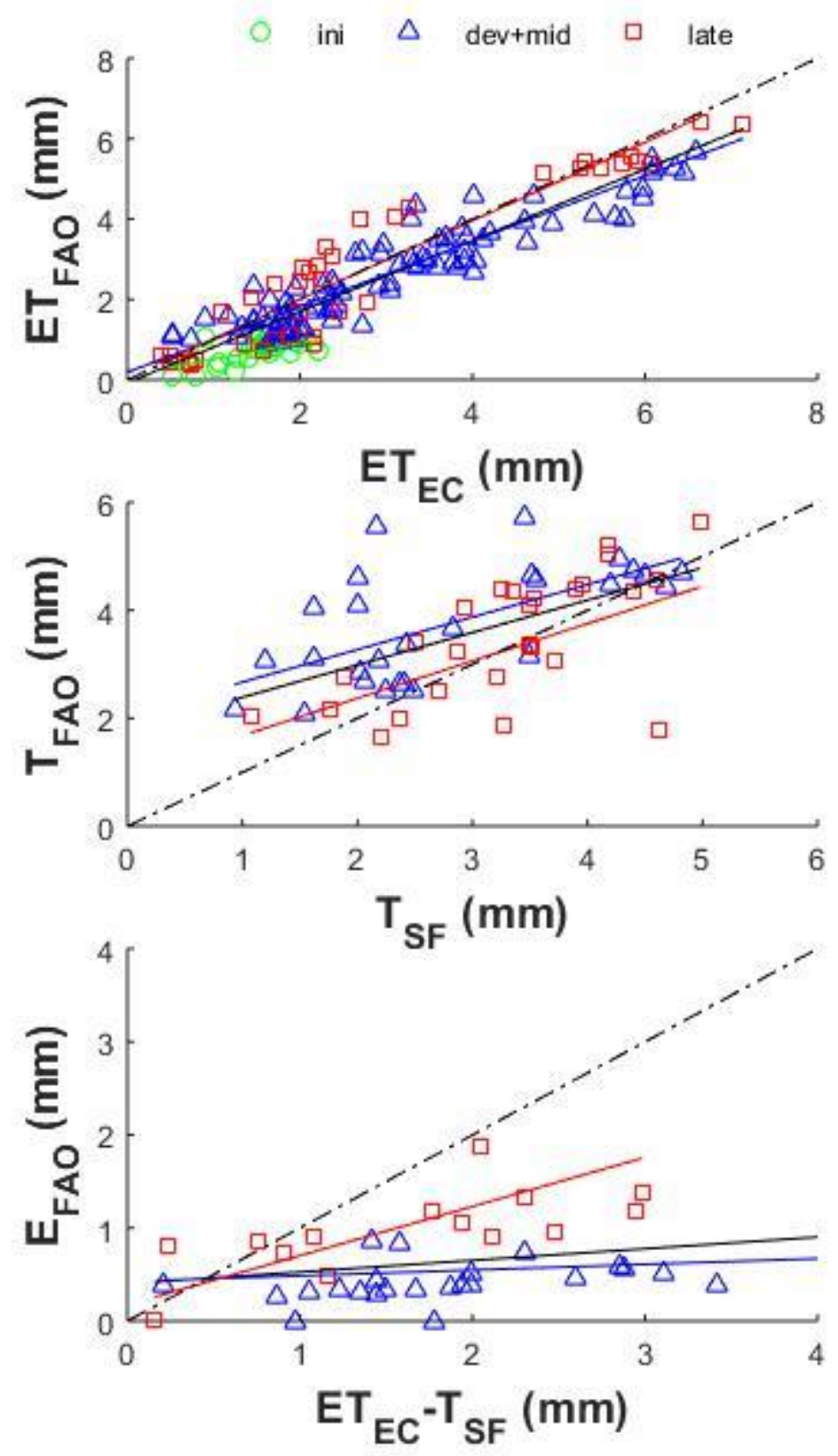

Figure 5: Same as Figure 4, but for the reference field.

\subsubsection{Transpiration}

416 Four different methods are assessed to estimate the T component: FAO-2Kc model, SF sensors $\left(\mathrm{T}_{\mathrm{SF}}\right)$, the combination $\left(\mathrm{ET}_{\mathrm{Lys}}-\mathrm{E}_{\mathrm{Lys}}\right)$ of both Lys set up over transpiring $\left(\mathrm{ET}_{\mathrm{Lys}}\right)$ and non-transpirating $\left(\mathrm{E}_{\mathrm{Lys}}\right)$ wheat, and the combination $\left(\mathrm{ET}_{\mathrm{EC}}-\mathrm{E}_{\mathrm{Lys}}\right)$ between $\mathrm{EC}$ and Lys. It is reminded that the FAO-2Kc and SF techniques are implemented over both (controlled stress and reference) experimental fields, while the two Lys operate in the controlled stress field 421 only.

422 Figures 4 and 5 present the scatterplots of FAO-simulated versus observed (SF- and Lys423 derived) $\mathrm{T}$ while Figures $6 \mathrm{a}$ and $6 \mathrm{c}$ show the temporal evolution of T estimates from DOY 65 
to DOY 135 over the controlled stress and reference field, respectively. All three independent estimates are generally consistent. At first order, the dynamics of $T$ follow the atmospheric demand on a day-to-day basis. It also increases with both the irrigation frequency and wheat development until DOY 107 when senescence starts. Note that SF-derived and FAOsimulated T are very close from DOY 90 to DOY 118 over the reference field (Figure 6c). All three $\mathrm{T}$ methods consistently provide generally higher $\mathrm{T}$ values in the reference field than in the controlled stress field, with a maximum $\mathrm{T}$ of 5.6 (5.0) $\mathrm{mm}$ and 5.2 (4.1) $\mathrm{mm}$ for the FAO model (SF method), respectively. Note that the large peak in Lys data reaching $5.8 \mathrm{~mm}$ on DOY 107 over the controlled stress field is probably attributed to wetter conditions inside the Lys than outside on that particular wet date.

The SF-derived T estimates of both fields are of similar amplitude before DOY 85 (see Figure $6 a$ and 6c) despite the irrigation water shortage from DOY 65 to DOY 85 at the controlled stress field. This may be due to the relatively low climatic demand during that period while the soil water content was very different between the two plots. After DOY 85, the SF-derived $\mathrm{T}$ of the reference field is clearly superior to that of the controlled stress field. In fact, the impact of water deficit on wheat $\mathrm{T}$ is highly dependent on the atmospheric evaporative demand.

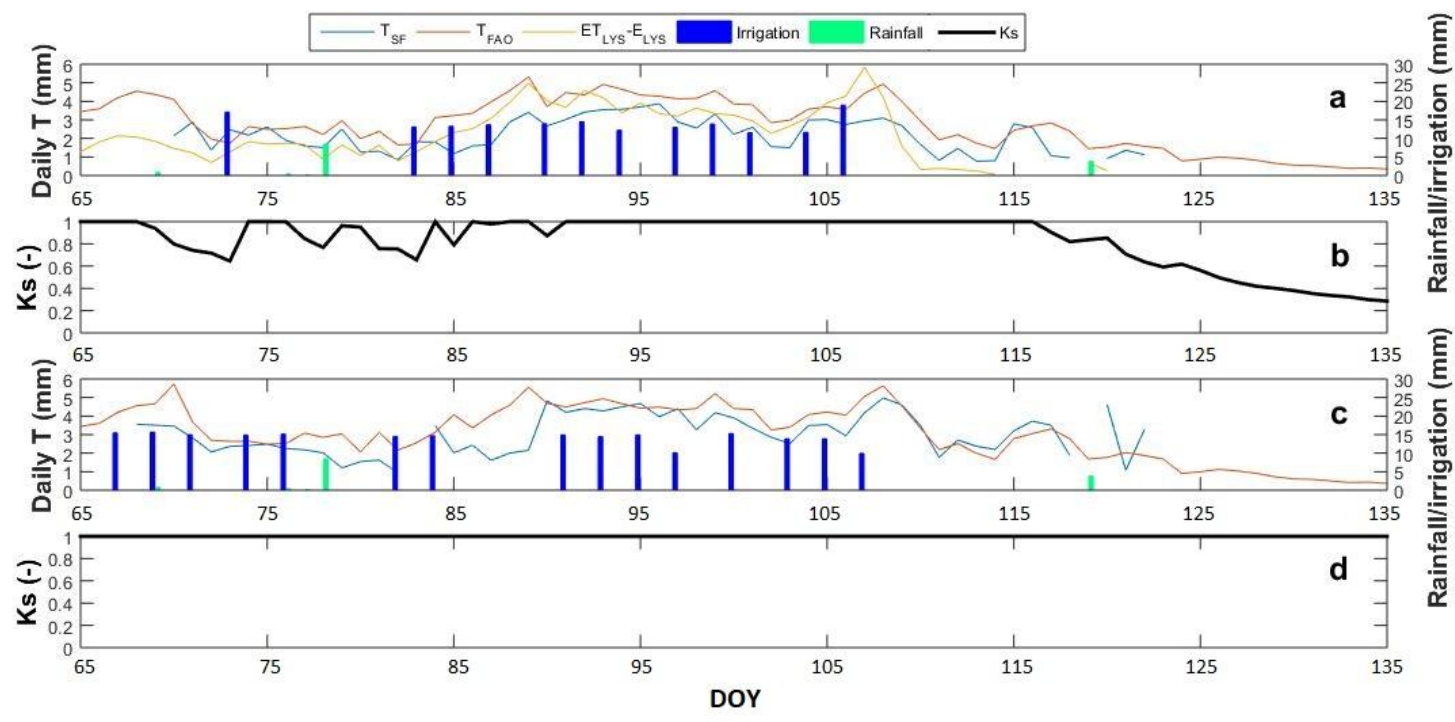

Figure 6: Time series of FAO-simulated, Lys-, SF-derived T and stress coefficient (Ks) over the controlled stress $(a, b)$ and reference $(c, d)$ field.

Over the controlled stress field, the difference between the Lys- and SF-derived $\mathrm{T}$ is rather variable. Lys tends to overestimate $\mathrm{SF}$-derived $\mathrm{T}$ in wet conditions and underestimate SFderived $\mathrm{T}$ in dry conditions, similarly to the EC/Lys comparison in the ET case described previously. However, when comparing all three approaches (FAO, SF and Lys), SF-derived T is generally lower than both FAO and Lys estimates during the crop development. This effect is more visible for the controlled stress field than for the reference field where FAO and SF methods match relatively well (except from DOY 85 to DOY 90). The slight underestimation of SF-derived $\mathrm{T}$ could be attributed to issues in the up-scaling technique from the 3-5 monitored stems to the field scale. 
Table 2 lists the statistical results between modeled and measured $\mathrm{T}$ for the controlled stress and reference fields separately. The MD between FAO-simulated and Lys-, SF-, and EC-Lysderived $\mathrm{T}$ is $-1.01,-0.99$, and $-1.17 \mathrm{~mm}$, respectively. The $\mathrm{T}$ modeled by FAO-2Kc is generally larger than that of all three methods: SF, Lys-only and EC and Lys combined (ET $\mathrm{EC}^{-}$ $\left.E_{\text {Lys }}\right)$. The overestimation of the model is clearly seen in the scatterplots of Figure 4 (controlled stress field). Such phenomenon is also observed on the reference field (Figure 5) although the difference between FAO-simulated and SF-derived $\mathrm{T}$ is smaller between DOY 90 and DOY 110, when the vegetation was fully covering the soil (as opposed to the controlled stress field) so that $\mathrm{E}$ was minimized by the vegetation screening effect. Given that the FAO model has not a significant bias on ET estimates during the development stage, a direct consequence of the overestimation of $\mathrm{T}$ by the FAO model is its underestimation of $\mathrm{E}$. This result is fully consistent with the systematic underestimation of ET by FAO-2Kc during the initial stage (see previous discussion about ET estimates).

\subsubsection{Evaporation}

Figures 4 and 5 present the scatterplots of FAO-simulated versus observed (Lys- and EC/SFderived) $\mathrm{E}$ while Figures $7 \mathrm{a}$ and $7 \mathrm{~b}$ shows the temporal evolution of $\mathrm{E}$ estimates from DOY 65 to DOY 135 for the controlled stress and reference field, respectively. The model underestimates E, especially during relatively dry periods. This result is consistent with previous discussions on 1) the underestimation of ET by the FAO model during the initial period (when $\mathrm{E}$ is dominant) and 2) the overestimation of $\mathrm{T}$ (at the expense of $\mathrm{E}$ ) during the crop development period. However, the underestimation of $\mathrm{E}$ by FAO-2Kc can be compensated by an overestimation of $\mathrm{T}$, thus providing quite satisfying results in terms of $\mathrm{ET}$ estimates, especially during the crop development period. This result is consistent with that obtained by Er-Raki et al. (2007) on wheat crop, for flood-irrigation, under semi-arid climate.

Very low slopes (in the range -0.2-0.2 during the development phase) of the linear regression between modeled and observed $\mathrm{E}$ are reported in Table 2 . The generally poor correlation between modeled and observed $\mathrm{E}$ is notably due to a much faster drying of the SSM in the FAO model than in the Lys (Pruitt and Lourence, 1985; Allen et al., 2011). The FAOsimulated E drops quickly (and at an earlier stage than Lys mass) after an irrigation event and neglects $\mathrm{E}$ in relatively dry conditions during which Lys measures a minimum $\mathrm{E}$ rate of 0.5 $\mathrm{mm}$ per day (see Figure 7a). Interestingly enough, the FAO-simulated $\mathrm{E}$ is getting closer to the Lys-derived estimate during the wettest period from DOY 85 to DOY 105. In dry conditions (for NSSM <0.4), the FAO-simulated E is generally estimated as 0 , regardless of the remaining soil water availability (see Figure 5 for E) although the $100 \%$ vegetation coverage was never reached on this field during the experiment. It is suggested that the FAO formalism is not able to simulate E accurately in the full SSM range (Allen et al., 2011; Gharsallah et al., 2013). Note that the same results were obtained in Er-Raki et al. (2007) and Saadi et al. (2015) for irrigated and rainfed cereals under semi-arid climate. 


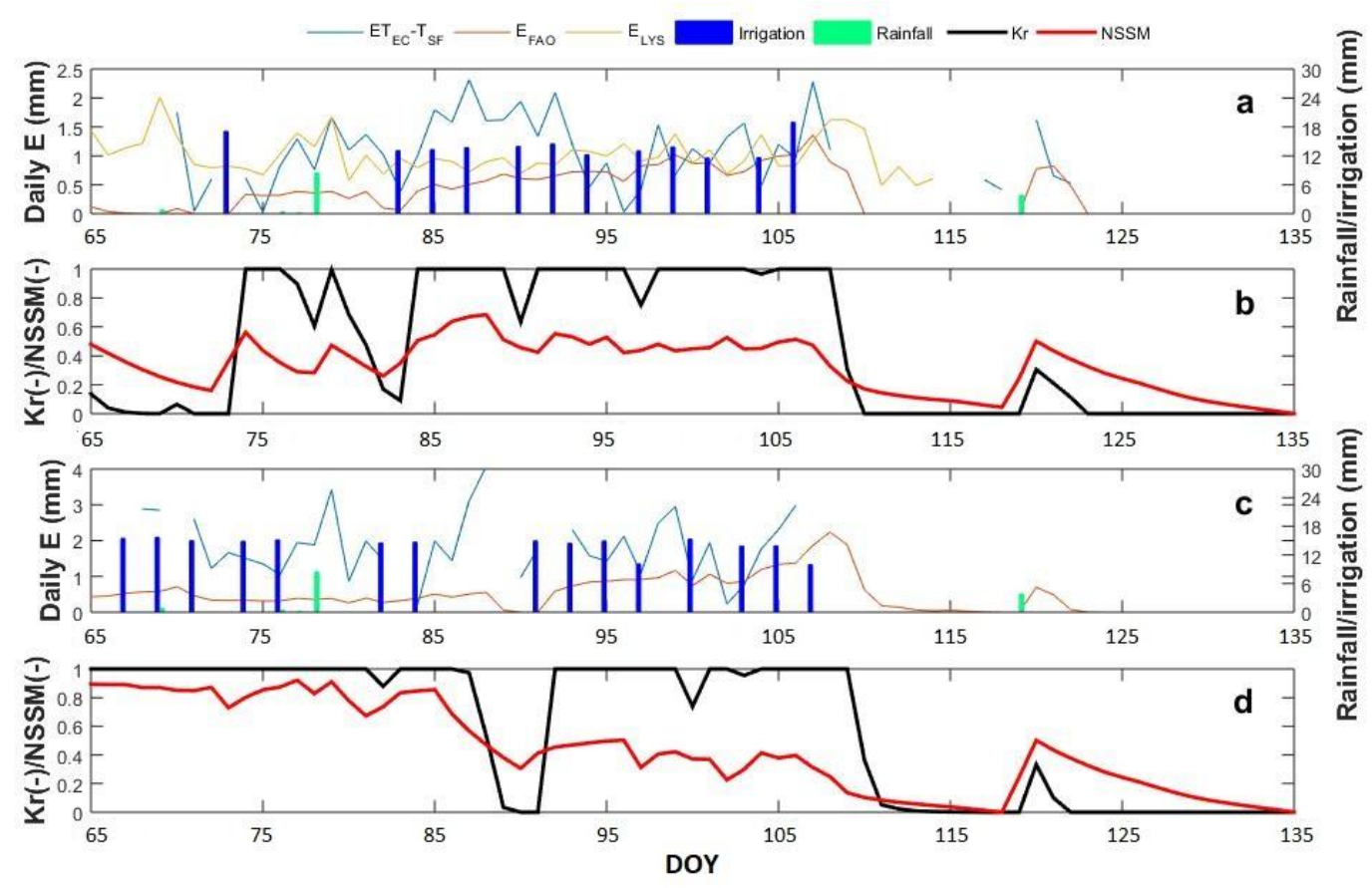

491

492

493

494

495

496

497

498

499

500

501

502

503

504

505

506

507

508

509

510

511

512

513

514

515

Figure 7: Time series of FAO-simulated and EC/SF-derived and Lys-derived E, E reduction coefficient $(\mathrm{Kr})$ and NSSM over the controlled stress $(\mathrm{a}, \mathrm{b})$ and reference $(\mathrm{c}, \mathrm{d})$ field.

EC/SF-derived $\mathrm{E}$ is not stable and varies rapidly on both controlled stress (Figure 7a) and reference (Figure 7c) fields. Although the mean E values obtained by Lys and EC/SF methods are similar (and consistently larger than the mean FAO-simulated E), large differences between Lys- and EC/SF-derived daily estimates are visible in Figure 7a all along the study period. Indeed, the combination of EC and SF data is likely to increase the uncertainty in E estimates because two independent measurements are used (with their respective spatial extent and uncertainty) and because E is significantly smaller than ET and T during the development phase.

3.2 Random uncertainties in ET, T and E estimates

\subsubsection{Controlled stress field}

The main impact of the correction using Equation (6) is evident with a MD close to zero in all cases (Table 2). In particular, the underestimation of ET by FAO model during the initial period no longer appears (Figure 8). Similarly, the overestimation of T by FAO model during the development period is reduced to approximately zero. Meanwhile, the correlation of $\mathrm{F}_{\mathrm{FAO}, \mathrm{Obs}}$ (derived from Equation 6) vs $\mathrm{F}_{\mathrm{Obs}}$ is systematically closer to 1 than the correlation of $\mathrm{F}_{\mathrm{Obs} \text {,roll }} \mathrm{vs} \mathrm{F}_{\mathrm{Obs}}$. More interesting are the relative magnitudes of $\mathrm{R}^{2}$ for each measurement method and the magnitude of the changes in $\mathrm{R}^{2}$ before and after correction. In terms of ET notably, the highest $\mathrm{R}^{2}$ without correcting FAO estimates is attributed to EC ( 0.74 in Table 2) while the highest $\mathrm{R}^{2}$ with the correction is attributed to Lys (0.89 in Table 2). In terms of T, the highest $R^{2}$ is attributed to Lys without (0.67 in Table 2$)$ and with $(0.85$ in Table 2$)$ the correction. By considering that the relative magnitude of $\mathrm{R}^{2}$ is an indicator of the relative random uncertainty in measurement methods, Lys represents the most precise method for 
estimating ET and T. The Lys method actually relies on a direct measure of the water weight, which is very precisely estimated. Moreover, both Lys and the FAO-2Kc model are based on the water balance, which may also explain this relatively low uncertainty of Lys data compared to corrected FAO-simulated flux estimates.

Regarding the E term, analysis is more complex as the FAO model is found to be poorly correlated with both Lys and EC/SF measurements, due to 1) a too fast drying of the top soil layer in the FAO modeling and 2) long periods with modeled E set to zero. Therefore, the assumption (i.e. linearity of possible biases in FAO flux estimates) on which the correction approach is based is invalid for E. Although Equation (13) is still applied to E as a first guess estimate of the relative random uncertainty in Lys and EC/SF measurements, one bears in mind that the corrected FAO-simulated $\mathrm{E}$ is unlikely to provide a robust reference for comparison purposes.

As a step further, the standard deviation between corrected FAO-simulated and measured fluxes is computed in all cases to estimate the relative random uncertainty of each method and for each flux (ET, T and E) separately. The relative random uncertainty in ET is 10\%, 7.6\% and $12 \%$ for EC, Lys and Lys/SF respectively. The estimated uncertainty in $\mathrm{T}$ is $15 \%, 12 \%$ and $17 \%$ for SF, Lys and EC/Lys, and the estimated uncertainty in E is $18 \%, 29 \%$ and $24 \%$ for Lys, EC/SF and Lys/SF, respectively.
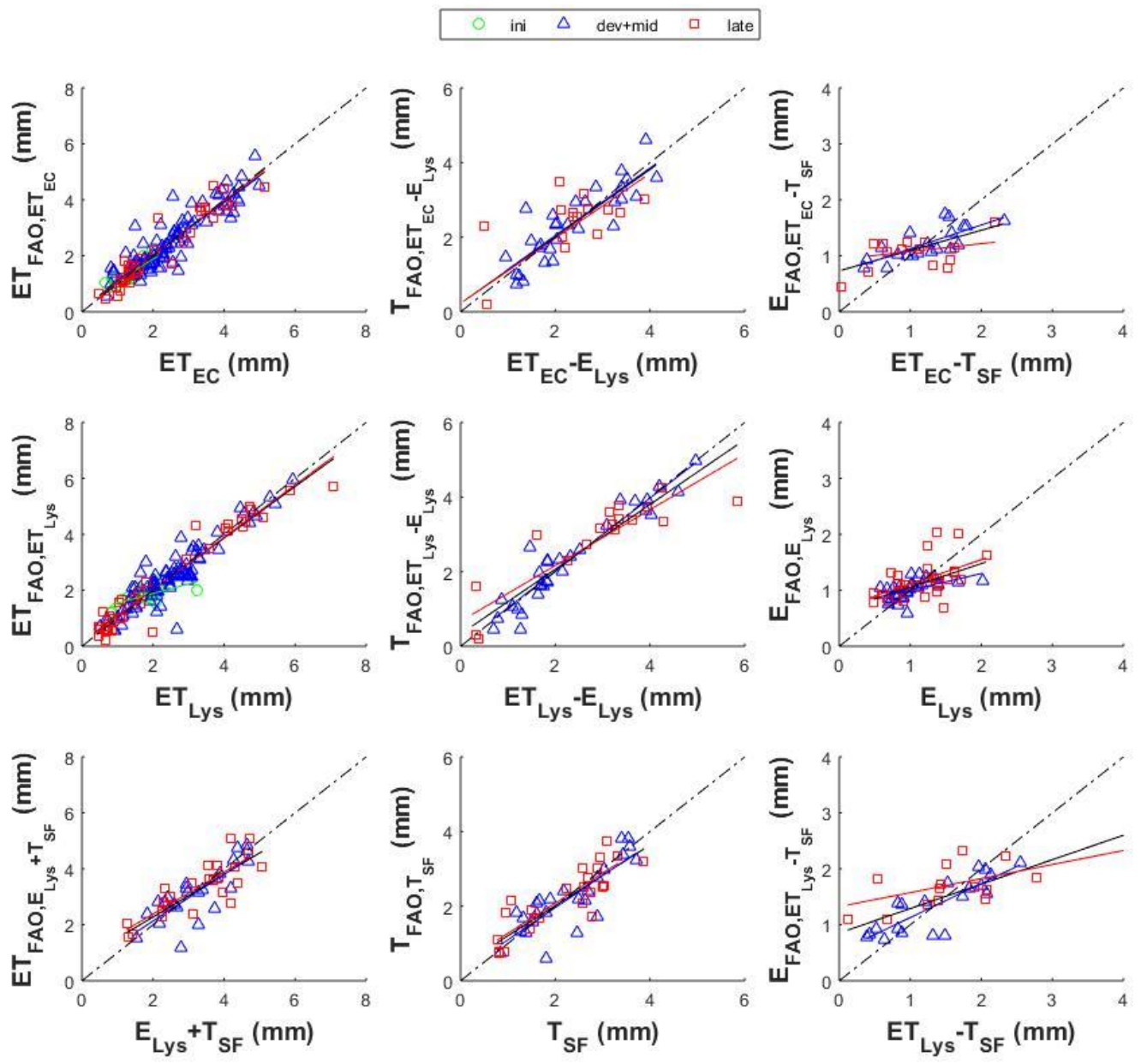
Figure 8: Scatterplot of corrected FAO-simulated versus measured fluxes over the controlled stress field.

\section{$537 \quad 3.2 .2$ Reference field}

538 Figure 9 presents the scatterplots between corrected FAO-simulated and measured ET, T and 539 E separately. Results are similar to those obtained previously for the controlled stress field. 540 The $\mathrm{R}^{2}$ is $0.92(0.86)$ for ET, $0.59(0.71)$ for $\mathrm{T}$ and $0.33(0.44)$ for $\mathrm{E}$ over the reference 541 (controlled stress) field, respectively (Table 2). The higher scatter of $\mathrm{T}$ estimates is attributed 542 to the first part of the development period (from DOY 65 to DOY 90) when the daily 543 difference between corrected FAO-simulated and SF-derived $\mathrm{T}$ is significant. Results in terms 544 of E estimates are also quite consistent for both fields, with a generally low sensitivity of the 545 FAO model to variations in $\mathrm{E}$ measurements, implying a low $\mathrm{R}^{2}$ between corrected FAO546 simulated and EC-SF measured E. The relative random uncertainty is $8.3 \%, 14 \%$ and $33 \%$ for 547 EC-derived ET, SF-derived T and EC/SF-derived E, respectively. 

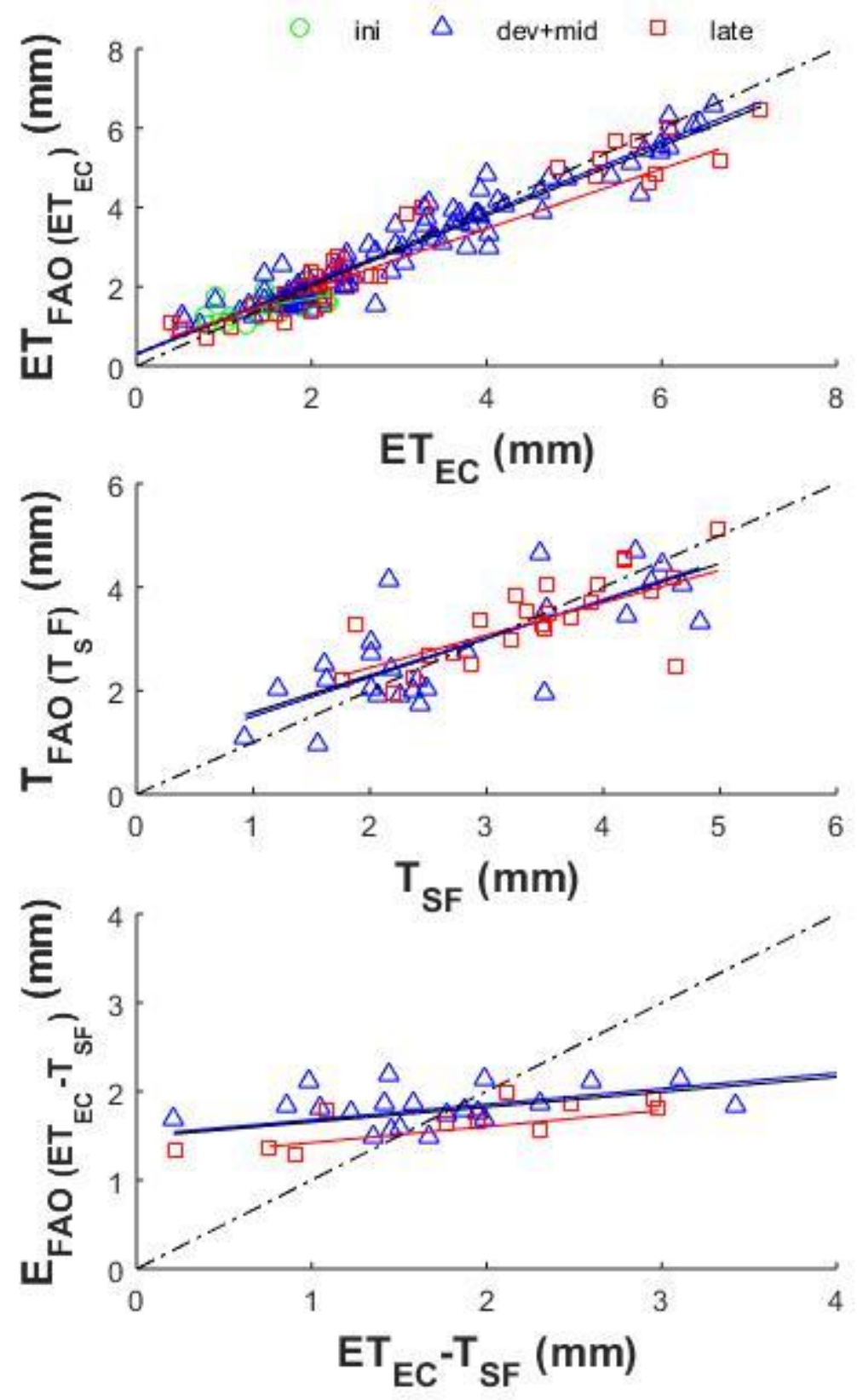

548

549 Figure 9: Scatterplot of corrected FAO-simulated versus measured fluxes over the reference 550 field. 
551 Table 2: Statistical results in terms of determination coefficient $\left(\mathrm{R}^{2}\right)$, root mean square difference (RMSD), mean difference (MD), slope and intercept 552 of the linear regression between FAO-simulated and measured fluxes before and after correction over the controlled stress and reference field.

\begin{tabular}{|c|c|c|c|c|c|c|c|c|c|c|c|c|c|c|c|c|c|c|c|c|c|c|c|}
\hline \multirow{2}{*}{ Field } & \multirow{2}{*}{ Correction } & \multirow{2}{*}{ Flux } & \multirow{2}{*}{ Method } & \multicolumn{4}{|c|}{$\mathrm{R}^{2}$} & \multicolumn{4}{|c|}{ RMSD (mm) } & \multicolumn{4}{|c|}{$\mathrm{MD}(\mathrm{mm})$} & \multicolumn{4}{|c|}{ Slope } & \multicolumn{4}{|c|}{ Intercept (mm) } \\
\hline & & & & All & ini & dev+mid & late & All & ini & dev+mid & late & All & ini & dev+mid & late & All & ini & dev+mid & late & All & \begin{tabular}{|l|} 
ini \\
\end{tabular} & dev+mid & late \\
\hline \multirow{16}{*}{ 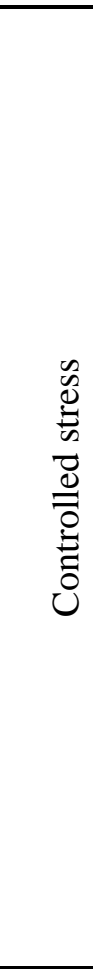 } & \multirow{8}{*}{ No } & \multirow{3}{*}{ ET } & $\mathrm{ET}_{\mathrm{EC}}$ & 0.75 & 0.68 & 0.74 & 0.80 & 0.75 & 0.23 & 0.51 & 0.49 & -0.05 & 0.55 & $\begin{array}{l}0.01 \\
\end{array}$ & -0.51 & 1.19 & 0.59 & 1.12 & 1.32 & -0.38 & 0.04 & $\begin{array}{l}-0.30 \\
\end{array}$ & -0.14 \\
\hline & & & $\mathrm{ET}_{\text {Lys }}$ & 0.66 & 0.13 & 0.55 & 0.86 & 0.82 & 0.33 & 0.64 & 0.39 & -0.03 & 0.81 & -0.03 & -0.44 & 0.91 & 0.22 & 0.89 & 0.90 & 0.23 & 0.56 & 0.30 & 0.66 \\
\hline & & & $\mathrm{E}_{\mathrm{Lys}}+\mathrm{T}_{\mathrm{SF}}$ & 0.55 & - & 0.52 & 0.58 & 0.55 & - & 0.40 & 0.38 & -0.41 & - & -0.44 & -0.41 & 1.02 & - & 1.08 & 1.03 & 0.33 & - & 0.19 & 0.31 \\
\hline & & \multirow{3}{*}{$\mathrm{T}$} & $\mathrm{T}_{\mathrm{SF}}$ & 0.63 & - & 0.53 & 0.74 & 0.66 & - & 0.50 & 0.44 & -0.99 & - & -1.00 & -1.01 & 1.00 & - & 1.01 & 1.04 & 1.00 & - & 0.97 & 0.92 \\
\hline & & & $\mathrm{ET}_{\text {Lys }}-\mathrm{E}_{\text {Lys }}$ & 0.67 & - & 0.66 & 0.73 & 0.72 & - & 0.56 & 0.43 & -1.01 & - & -1.11 & -0.86 & 0.65 & - & 0.75 & 0.56 & 1.83 & - & 1.68 & 1.88 \\
\hline & & & $\mathrm{ET}_{\mathrm{EC}}-\mathrm{E}_{\mathrm{Lys}}$ & 0.62 & - & 0.66 & 0.60 & 0.77 & - & 0.52 & 0.55 & -1.17 & - & -1.03 & -1.36 & 0.85 & - & 1.00 & 0.78 & 1.48 & - & 1.02 & 1.73 \\
\hline & & \multirow{2}{*}{ E } & $\mathrm{E}_{\mathrm{Lys}}$ & 0.00 & - & 0.04 & 0.00 & 0.54 & - & 0.34 & 0.41 & 0.71 & - & 0.68 & 0.74 & -0.01 & - & -0.17 & 0.01 & 0.40 & - & 0.50 & 0.43 \\
\hline & & & $\mathrm{ET}_{\mathrm{Lys}}-\mathrm{T}_{\mathrm{SF}}$ & 0.50 & - & 0.52 & 0.61 & 0.50 & - & 0.36 & 0.34 & 0.72 & - & 0.81 & 0.65 & 0.26 & - & 0.23 & 0.27 & 0.22 & - & 0.14 & 0.36 \\
\hline & \multirow{8}{*}{ Yes } & \multirow{3}{*}{ ET } & $\mathrm{ET}_{\mathrm{EC}}$ & 0.86 & 0.78 & 0.81 & 0.90 & 0.39 & 0.07 & 0.34 & 0.18 & -0.01 & 0.00 & -0.01 & -0.01 & 0.95 & 0.79 & 0.93 & 0.98 & 0.13 & 0.30 & 0.18 & 0.06 \\
\hline & & & $\mathrm{ET}_{\text {Lys }}$ & 0.89 & 0.43 & 0.85 & 0.94 & 0.40 & 0.14 & 0.31 & 0.22 & 0.01 & -0.01 & 0.02 & 0.00 & 0.92 & 0.34 & 0.94 & 0.94 & 0.17 & 1.20 & 0.13 & 0.15 \\
\hline & & & $\mathrm{E}_{\mathrm{Lys}}+\mathrm{T}_{\mathrm{SF}}$ & 0.67 & - & 0.65 & 0.70 & 0.32 & - & & 0.22 & 0.01 & - & 0.07 & -0.09 & 0.76 & - & 0.83 & 0.75 & 0.75 & - & 0.47 & 0.89 \\
\hline & & \multirow{3}{*}{$\mathrm{T}$} & $\mathrm{T}_{\mathrm{SF}}$ & 0.71 & - & 0.70 & 0.72 & 0.26 & - & 0.19 & 0.17 & 0.02 & - & 0.08 & -0.06 & 0.81 & - & 0.86 & 0.81 & 0.39 & - & 0.24 & 0.47 \\
\hline & & & $\mathrm{ET}_{\mathrm{Lys}}-\mathrm{E}_{\mathrm{Lys}}$ & 0.85 & - & 0.91 & 0.79 & 0.28 & - & 0.15 & 0.23 & 0.00 & - & -0.01 & 0.01 & 0.87 & - & 0.98 & 0.75 & 0.33 & - & 0.05 & 0.67 \\
\hline & & & $\mathrm{ET}_{\mathrm{EC}}-\mathrm{E}_{\mathrm{Lys}}$ & 0.70 & - & 0.74 & 0.63 & 0.31 & - & 0.21 & 0.24 & 0.00 & - & -0.01 & 0.03 & 0.90 & - & 0.91 & 0.87 & 0.23 & - & 0.23 & 0.23 \\
\hline & & \multirow{2}{*}{$\mathrm{E}$} & $\mathrm{E}_{\mathrm{Lys}}$ & 0.31 & - & 0.29 & 0.28 & 0.18 & - & 0.11 & 0.15 & 0.00 & - & -0.01 & -0.01 & 0.42 & - & 0.30 & 0.43 & 0.64 & - & 0.71 & 0.68 \\
\hline & & & $\mathrm{ET}_{\mathrm{Lys}}-\mathrm{T}_{\mathrm{SF}}$ & 0.54 & - & 0.70 & 0.40 & 0.25 & - & 0.12 & 0.22 & -0.01 & - & 0.01 & 0.00 & 0.44 & - & 0.61 & 0.25 & 0.85 & - & 0.52 & 1.32 \\
\hline \multirow{6}{*}{ 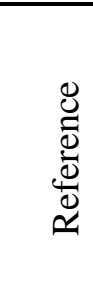 } & \multirow{3}{*}{ No } & ET & $\mathrm{ET}_{\mathrm{EC}}$ & 0.85 & 0.35 & 0.87 & 0.84 & 0.71 & 0.34 & 0.55 & 0.29 & 0.38 & 0.79 & 0.39 & 0.00 & 0.89 & 0.40 & 0.82 & 0.98 & -0.07 & 0.10 & 0.19 & 0.05 \\
\hline & & $\mathrm{T}$ & $\mathrm{T}_{\mathrm{SF}}$ & 0.34 & - & 0.44 & 0.38 & 0.64 & - & 0.55 & 0.32 & -0.57 & - & -0.89 & -0.01 & 0.60 & - & 0.60 & 0.69 & 1.79 & - & 2.07 & 0.99 \\
\hline & & $\mathrm{E}$ & $\mathrm{ET}_{\mathrm{EC}}-\mathrm{T}_{\mathrm{SF}}$ & 0.08 & - & 0.04 & 0.67 & 0.69 & - & 0.67 & 0.16 & 1.17 & - & 1.31 & 0.58 & 0.12 & - & 0.06 & 0.53 & 0.40 & - & 0.43 & 0.18 \\
\hline & \multirow{3}{*}{ Yes } & ET & $\mathrm{ET}_{\mathrm{EC}}$ & 0.92 & 0.32 & 0.93 & 0.90 & 0.43 & 0.13 & 0.34 & 0.23 & 0.05 & 0.00 & 0.03 & 0.16 & 0.88 & 0.38 & 0.89 & 0.76 & 0.29 & 0.94 & 0.32 & 0.44 \\
\hline & & $\mathrm{T}$ & $\mathrm{T}_{\mathrm{SF}}$ & 0.59 & - & 0.61 & 0.50 & 0.38 & - & 0.32 & 0.22 & 0.00 & - & -0.02 & 0.03 & 0.72 & - & 0.75 & 0.63 & 0.86 & - & 0.76 & 1.19 \\
\hline & & $E$ & $\mathrm{ET}_{\mathrm{EC}}-\mathrm{T}_{\mathrm{SF}}$ & 0.33 & - & 0.35 & 0.84 & 0.33 & - & 0.31 & 0.12 & 0.01 & - & -0.04 & 0.36 & 0.17 & - & 0.17 & 0.18 & 1.48 & - & 1.51 & 1.24 \\
\hline
\end{tabular}




\subsubsection{Daily uncertainty in SF-derived T}

To further investigate the random uncertainty in SF measurements, a statistical analysis is undertaken at the daily time scale by exploiting the 3 to 5 SF sensors that were operating simultaneously over each crop field. In practice, the standard deviation of daily individual estimates is computed for each field. Figure 10 shows the evolution of the daily mean and standard deviation of SF-derived $\mathrm{T}$ for both experimental sites separately. The daily standard deviation generally increases with $\mathrm{T}$ and the variation of the standard deviation is greater on the stressed than on the reference plot. A relatively small standard deviation is visible in Figure 10 from DOY 65 to DOY 85. This duration is characterized by a lack of irrigation water as mentioned above. From DOY 85 to DOY 110, the standard deviation is larger. The increase in standard deviation between both periods can be explained by the impact of the water supply shortage, in addition to drip irrigation that wets only $30 \%$ of soil. The partial wetting of soil may involve differences in $\mathrm{T}$ between wheat stems depending on their position relative to the irrigation tube. On the contrary, the reference plot was well irrigated throughout the cultivation stages and allowed the wheat stems to maintain a good uniformity.
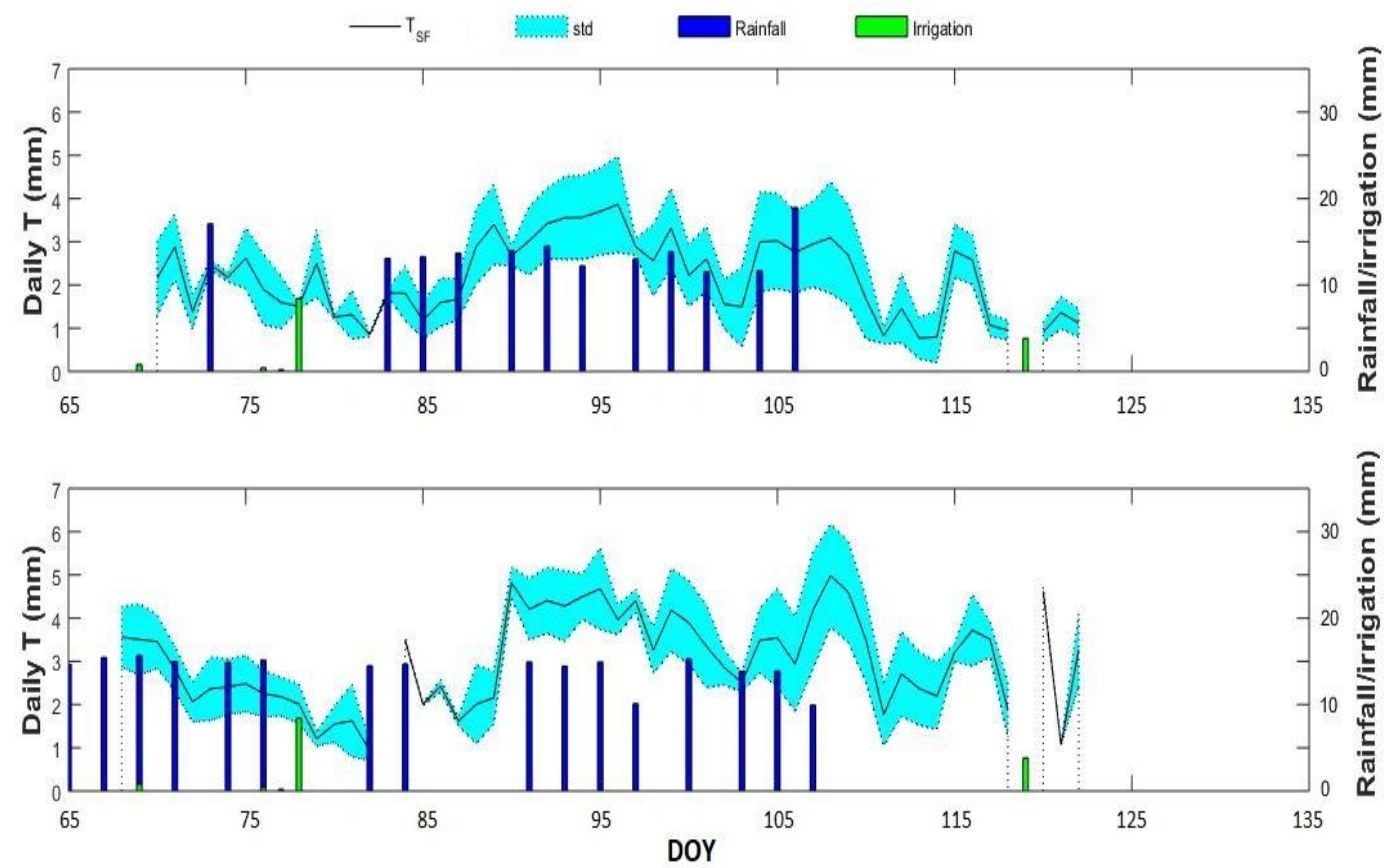

Figure 10: Time series of the daily mean and standard deviation of SF-derived T over the controlled stress (top) and reference (bottom) field.

\subsection{T/ET ratio:}

Previous analyses about systematic and random uncertainties in ET, T and E estimates are used to quantify the relative accuracy in the partitioning ratio and to interpret its dynamics at the daily and seasonal time scales.

\subsubsection{Controlled stress field}


Figures $11 \mathrm{a}$ and $11 \mathrm{~b}$ show the evolution of the T/ET ratios derived from Lys and Lys/EC data, respectively from DOY 65 to 114 . Both dynamics are fully consistent, given the strong coherence between Lys- and EC-derived ET estimates. The T/ET value is about 0.5 at DOY 65 , increases up to $0.8-0.9$ before the end of the middle-season phase, then keeps a relatively constant value until the beginning of senescence, and then suddenly drops to low values $(0.10$ 0.30) at about DOY 110. The increase of the partitioning ratio from DOY 65 to DOY 90 is associated with an increase of the irrigation frequency. It seems that the portion of $\mathrm{T}$ increases with the soil water availability. At the early stage of senescence, $\mathrm{T}$ decreases continually so that the T/ET ratio gets low values regardless of the soil water availability and the green fraction cover. Note that T/ET values larger than 1 are obtained on DOY 106-108 by combining Lys and EC data. This is due principally to the overestimation of EC-derived ET by the Lys technique in wet conditions. Nonetheless, both Lys- and Lys/EC-derived partitioning ratios provide consistent and physically sound variations all along middledevelopment and late phases.

Figures 11c and 11d plot the T/ET ratios derived from SF/EC and SF/Lys data, respectively. Both cases show an irregularity at the beginning of the measurement period (DOY 70 to DOY 75) as well as during the senescence period (from DOY 109). The suspicious behavior of SFderived T from DOY 70 to DOY 75 is probably due to a loose contact between the SF sensors and stems, which causes larges fluctuations of the SF output. Indeed, the water stress experienced by the controlled stress wheat may have caused a loss of tissue water, leading to a decrease in the turgidity of the cells, and subsequently a decrease in the size of the stems and hence in the quality of the contact with SF sensors. During senescence, another phenomenon occurs when the SF-derived T exceeds both EC-derived and Lys-derived ET. Such erroneous behavior of the T/ET ratio could be explained by the drying of wheat stems, resulting in a drastic change in the energy dissipation through the stem. Note that the SF-derived T/ET is generally difficult to interpret as the whole study period is characterized by unstable variations, which may be attributed to upscaling issues of the SF-derived T measured at 3-5 individual wheat stems only.

Figure 11e presents the evolution of the T/ET ratio modeled by FAO-2Kc during the season for the controlled stress field. This ratio varies between 0.86 and 1 and generally slightly decreases after irrigation or rainfall. The model's response to the water inputs is expected as the E component increases with the water availability in the soil surface. However, the FAOmodeled T/ET is much too close to 1 compared to all measured estimates, especially during relatively dry periods, the mid-season and the senescence phases. As discussed earlier, the model clearly underestimates E compared to the field measurements made in this experiment. This implies an over-estimation of the T/ET ratio, particularly after the cessation of irrigation for a few days (e.g. before DOY 83 and after DOY 106).

The correlation coefficient $(\mathrm{R})$ between the T/ET ratios and potential variability factors (NSSM, LAI and VPD) are reported in Table 3. Since the SF-derived T is clearly unreliable during the senescence period, all results are presented for both the entire partitioning period and, in parentheses, the same period by excluding the senescence period. The largest $\mathrm{R}$ $(+0.82)$ is obtained for Lys-derived T/ET with NSSM. The variations of the partitioning ratio 
618 derived from Lys data are thus easier to interpret from potential variability factors (such as 619 NSSM) than those of the other T/ET estimates. This is consistent with the previous 620 assessment of systematic and random uncertainties in measurement techniques, demonstrating 621 that Lys provides reasonable E/T estimates. However, the positive sign of the correlation

622 between Lys-derived T/ET and NSSM is unexpected as the E portion should increase with 623 SSM (Liu et al., 2002; Kang et al., 2003). In fact, our experiment was undertaken under semi624 arid conditions and after DOY 65, when the green LAI had already reached its maximum 625 value. It is hence suggested that, under such conditions, the SSM is a good proxy for the soil 626 water availability to T (instead of E). Consequently, the T portion increases with SSM while 627 the E underneath the wheat canopy is maintained at a relatively constant level. When looking 628 at SF-derived T/ET, a negative correlation is obtained with NSSM. The point is that this 629 correlation is significantly decreased (from -0.46 to -0.18 ) when excluding the senescence 630 period. Therefore, the statistical significance of this negative correlation is questionable. The 631 opposite sign of the correlations obtained for SF-derived and Lys-derived T/ET could be 632 attributed to the impact of the drying of stems (and water stress) on the SF-derived T. 633 Regarding VPD, the largest $\mathrm{R}(+0.6)$ is still obtained with Lys-derived T/ET. As VPD 634 characterizes the drying ability of air, plants tend to transpire more when VPD (moderately) 635 increases. The positive sign of the correlation between T/ET and VPD illustrates this effect, 636 by considering that $\mathrm{E}$ (underneath the wheat canopy) is less affected by VPD than T. 637 However, the correlation values are significantly lower than for NSSM. Regarding LAI, 638 correlations are very low for Lys-derived T/ET. Such result is expected as the partitioning 639 experiment started when wheat was already well developed. 


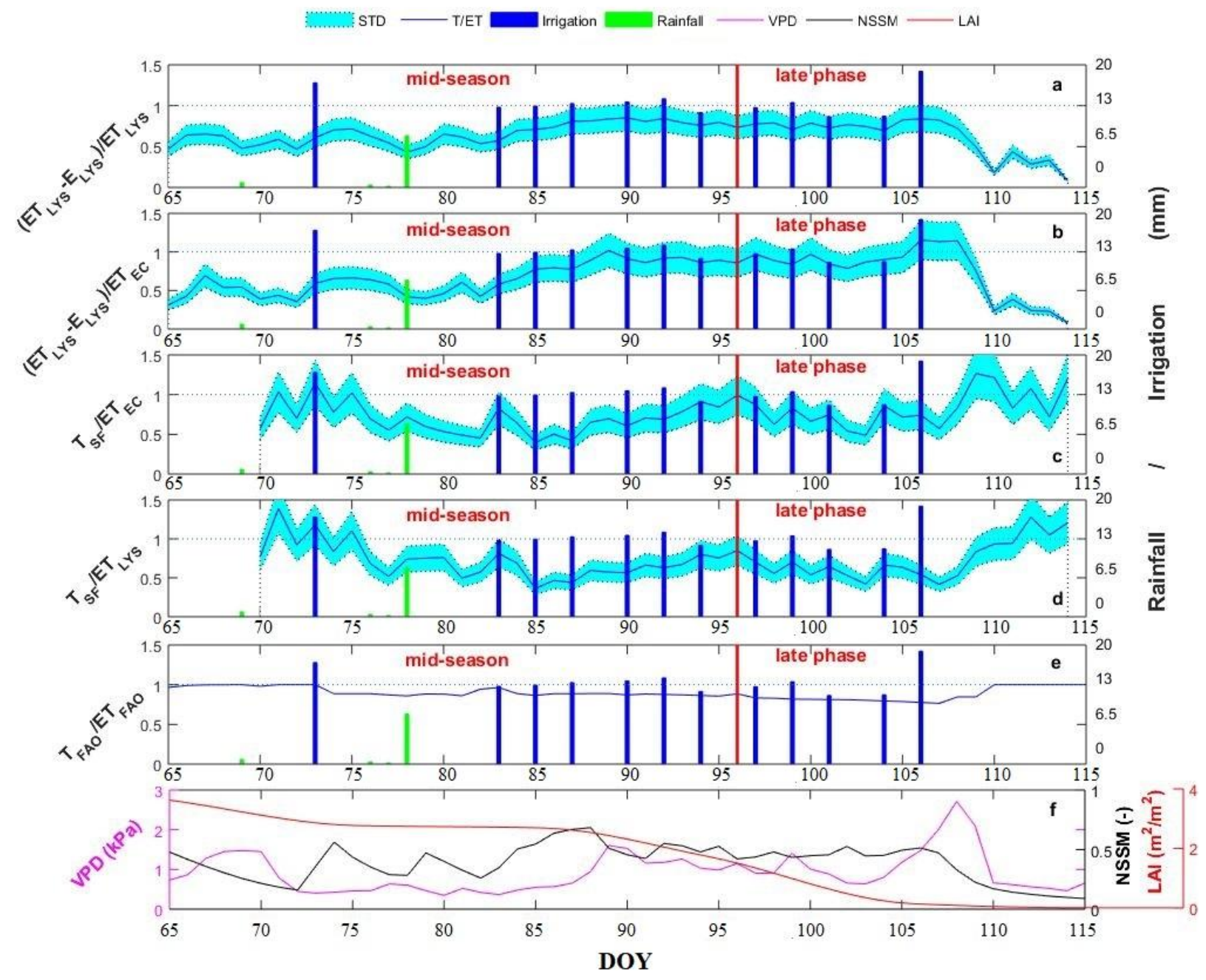

640

641

642

643

644

645

646

647

648

649

650

651

652

653

654

655

Figure 11: Evolution of the T/ET ratio, with its standard deviation, derived from Lys (a), Lys/EC (b), SF/EC (c), SF/Lys (d) and FAO (e) data over the controlled stress field. The dynamics of NSSM, LAI and VPD are also plotted for comparison (f).

\subsubsection{Reference field}

Figure 12a plots the T/ET ratio derived from SF/EC data over the reference field. Note that the gaps in T/ET data are mainly related to gaps in EC data. The large fluctuations observed over the controlled stress field at the beginning of the period do not appear over the reference field, as the reference field did not experience water stress and the stem diameter was sufficient to ensure a good contact with SF sensors as soon as DOY 65. However, the T/ET ratio also reached values larger than 1 at the end of the senescence stage, consistent with the results obtained over the controlled stress field. By removing the erroneous behavior of SFderived $\mathrm{T}$ after DOY 109, the partitioning ratio slightly increases during the study period, consistent with the Lys-derived T/ET ratio over the other (controlled stress) field. Over the reference field, the portion of SF/ET/Lys-derived E is relatively large as the soil was maintained near field capacity with frequent and regular irrigations. 

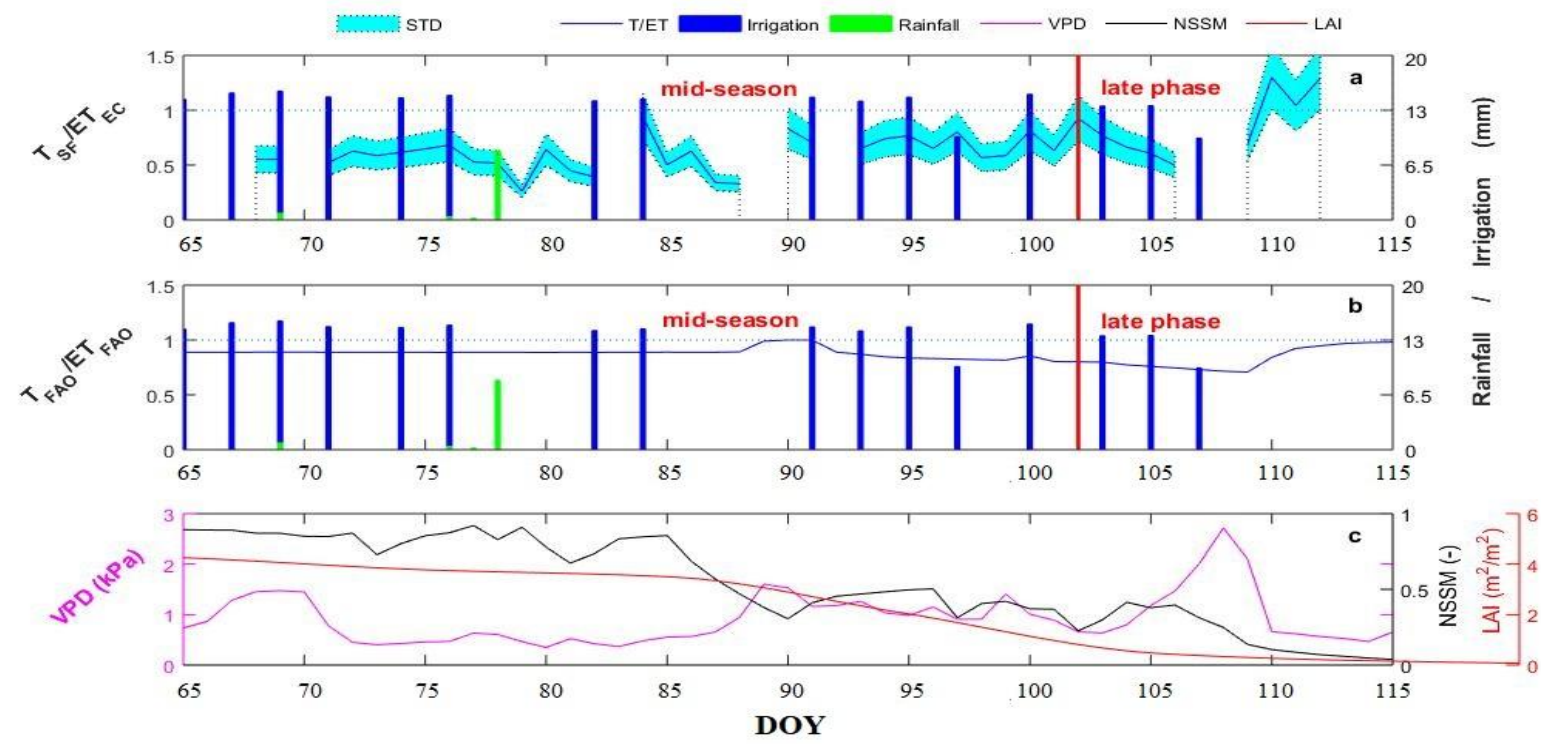

656

657

658

659

660

661

662

663

664

665

666

667

668

669

670

671

672

673

674

Figure 12: Evolution of the T/ET ratio, with its standard deviation, derived from SF/EC (a) and FAO (b) data over the reference field. NSSM, LAI and VPD are also plotted for comparison (c).

Table 3: Statistical results in terms of correlation coefficient (R) between T/ET ratios and variability factors (SSM, VPD and LAI) over the controlled stress and reference field separately for the entire study period (by excluding the senescence period in parenthesis).

\begin{tabular}{|c|c|c|c|c|}
\hline \multirow{2}{*}{ Field } & \multirow{2}{*}{$\mathrm{T} / \mathrm{ET}$} & \multicolumn{3}{|c|}{$\mathrm{R}$} \\
\cline { 3 - 5 } & & $\mathrm{SSM}$ & $\mathrm{VPD}$ & $\mathrm{LAI}$ \\
\hline \multirow{4}{*}{ Controlled stress } & $\mathrm{T}_{\mathrm{SF}} / \mathrm{ET}_{\mathrm{EC}}$ & $-0.46(-0.18)$ & $0.12(0.53)$ & $-0.38(-0.07)$ \\
\cline { 2 - 5 } & $\mathrm{T}_{\mathrm{SF}} / \mathrm{ET}_{\mathrm{LyS}}$ & $-0.64(-0.48)$ & $-0.30(-0.18)$ & $-0.08(0.34)$ \\
\cline { 2 - 5 } & $\left(\mathrm{ET}_{\text {Lys }}-\mathrm{E}_{\mathrm{LYS}}\right) / \mathrm{ET}_{\mathrm{LYS}}$ & $0.82(0.72)$ & $0.34(0.58)$ & $0.17(-0.57)$ \\
\cline { 2 - 5 } & $\left(\mathrm{ET}_{\mathrm{LYys}} \mathrm{E}_{\mathrm{LYS}}\right) / \mathrm{ET}_{\mathrm{EC}}$ & $0.69(0.62)$ & $0.57(0.46)$ & $-0.16(-0.72)$ \\
\hline Reference & $\mathrm{T}_{\mathrm{SF}} / \mathrm{ET}_{\mathrm{EC}}$ & $-0.61(-0.40)$ & $-0.02(0.12)$ & $-0.58(-0.35)$ \\
\hline
\end{tabular}

\section{Conclusion:}

The partitioning of the wheat field ET into $\mathrm{T}$ and $\mathrm{E}$ is subject to significant uncertainties due to both the large range ( 0 to 0.9 ) covered by the daily T/ET ratio and the difficulty in separating the $\mathrm{T}$ (or E) component from the total ET. Although past studies have been based on only two independent methods to represent three fluxes (E, T, and ET), an original experiment is proposed herein 1) to implement four independent methods including three measurement techniques (EC, Lys and SF) and one modeling approach (FAO-2Kc) over two drip-irrigated wheat fields with different irrigation regimes, 2) to assess the systematic and random uncertainties in each partitioning method and 3) to analyze the dynamics of the daily T/ET ratio in relation to several assumed variability factors including SSM, LAI and VPD. To the knowledge of the authors it is the first time that all four methods (EC, Lys, SF, FAO-2Kc) 
have been implemented simultaneously over a cropped field. Note that the FAO-2Kc is calibrated using EC and SF data beforehand.

One difficulty in evaluating $\mathrm{E}$ and $\mathrm{T}$ estimates in the case of a mixed cover is that there is no absolute reference partitioning method. Therefore, new approaches are developed to further assess the systematic and random uncertainties in E/T/ET estimates. Regarding systematic errors, each flux (E, T and ET) is estimated in four different ways and the inter-comparison of the four independent estimates provides an insight into possible discrepancies attributed to one given method. It is found that the FAO-2Kc underestimates $\mathrm{E}$ and overestimates $\mathrm{T}$ while providing accurate estimates of the total ET. Moreover, EC- and Lys-derived ET estimates are quite consistent, except in very wet (dry) conditions when the Lys tends to slightly overestimate (underestimate) ET-derived ET. Despite the small size of mini Lys $(30 \mathrm{~cm}$ in diameter), the discrepancy between EC- and Lys-derived ET is found to be minor compared to the uncertainties in the other flux estimates. SF-derived and Lys-derived $\mathrm{T}$ estimates are on average consistent during the middle-development phase, but significant differences are obtained at the daily scale. During senescence, the SF-derived T gets values larger than EC ET measurements, which indicates than SF sensors are not appropriate when the stems dry. Whereas all measurements techniques agree on the fact that FAO-2Kc underestimates E, only Lys provides E dynamics that are consistent with FAO-2Kc simulations.

Regarding random uncertainties, each measurement method is statistically compared against the FAO-2Kc simulated fluxes corrected over a sliding period. In practice, any potential bias in FAO-2Kc is removed at the weekly scale by subtracting the simulated to observed flux. The idea is to consider that the unbiased discrepancy between FAO and observed flux is proportional to the relative random uncertainty of a given measurement technique. It is found that the Lys is the most precise measurement method (more precise than EC and SF methods). The random uncertainty in SF-derived estimates is the largest due to 1) the small number (3-5 per crop field) of SF sensors used, which makes upscaling strategies difficult and 2) the impact of water stress (over the controlled stress field) and drying (over both controlled stress and reference fields) of wheat stems on the SF energy dissipation model.

Time series of the T/ET ratios derived from four different combinations of the EC, Lys and SF data sets collected from DOY 65 until senescence are finally analyzed. The T/ET ratio generally increases during the mid-season from about 0.50 to about 0.85 at maturity and then drops towards 0 during the senescence period. Interestingly, the T/ET ratio is highly and positively correlated with SSM, whereas no significant correlation is obtained with LAI. Such results are still consistent with past studies (Liu et al., 2002; Kang et al., 2003), which focused on the wheat development phases with increasing LAI, while our experiments started when the green LAI was already decreasing and lasted until the end of senescence. It is suggested that, in such an arid environment and during the phenological stages when the soil is well covered, SSM is a meaningful proxy for the soil water availability to wheat T. Even though the estimated relative random uncertainties in all the T/ET ratios are acceptable (they all range within 19\%-24\%), systematic errors in SF measurements lead to values larger than 1 during water-stress and senescence periods. Increasing the number of SF sensors could help reduce 
the random uncertainties of $\mathrm{T}$ estimates under well-watered conditions, especially by improving the upscaling of stem-based measurements to the field scale.

Results in this study show that the comparison between detailed (and high quality) measurements against model simulations of E, T and ET is essential to improve models. It is clear that such expensive instruments (eddy covariance, lysimeters, sap flow sensors) cannot be implemented extensively and that the assessment of water use patterns in irrigated crops will still rely on models such as the FAO-2Kc or other models. However, models are not exempt from uncertainties -including systematic biases- in simulated fluxes and soil moisture, especially when they are applied to specific conditions (i.e. drip irrigation) for which they have not been calibrated. In our case, drip irrigated wheat in semi-arid climate, the FAO-2Kc underestimates $\mathrm{E}$ compared to field measurements. This underestimation of $\mathrm{E}$ may be due to the representation of soil layers as simple reservoirs, which do not take into account the diffusion of water especially between the surface and the root-zone soil layers. To improve the modeling of the surface soil moisture dynamics, it is necessary to consider the capillary rise from the root zone. One question that still remains open is how to represent a complex phenomenon (e.g. water diffusion) using a limited input data set (meteorological measurements) and a simple (two-layer) discretization of the soil as in the FAO-2Kc formalism. Another avenue for research is to adapt the $\mathrm{Kr}$ representation to the nonlinear relationship between $\mathrm{E}$ and soil moisture in a range of soil types and surface conditions (Merlin et al., 2016; 2018).

This experiment provides a unique data set that will be used in the near future to improve land surface models like FAO-2Kc, dual source energy balance models (e.g. Ait Hssaine et al., 2018) and Soil Vegetation Atmosphere Transfer models (e.g. Boone et al., 2017), as the E/T partitioning exerts a strong physical constraint on the surface-atmosphere transfers. Moreover, new partition methods using EC data (e.g. Anderson et al., 2017) could be directly evaluated using the available independent E/T measurements. Estimates of $\mathrm{T}$ alone could also be used to investigate vegetation stress indices based on thermal infrared data, fluorescence and Photochemical Reflectance Index (Moreno et al., 2017; Drusch et al., 2017). Such research activities will improve our knowledge about the actual water needs of irrigated crops.

\section{Acknowledgment:}

Initial set up and maintenance of the field instrumentation have been funded by the Joint International Laboratory TREMA http://trema.ucam.ac.ma. This study was partly supported by the European Commission Horizon 2020 Programme for Research and Innovation (H2020) in the context of the Marie Sklodowska-Curie Research and Innovation Staff Exchange (RISE) action (REC project, grant agreement no 645642) and by the French Agence Nationale de la Recherche (MIXMOD-E project, ANR-13-JS06-003-01). Other funding was provided by SAGESSE (PPR program funded by the Moroccan Ministry of Higher Education Grant agreement no: PPR/2015/48). The First author was awarded the mobility researches trainings 
from the PHC Maghreb 32592VE/14MAG22. We especially thank the farmer Omar Rafi for giving access to his fields.

\section{References:}

Agam, N., Evett, S.R., Tolk, J.A., Kustas, W.P., Colaizzi, P.D., Alfieri, J.G., McKee, L.G., Copeland, K.S., Howell, T.A., Chávez, J.L., 2012. Evaporative loss from irrigated interrows in a highly advective semi-arid agricultural area. Adv. Water Resour. 50, 20-30.

Agam, N., 2014. Comment on "Microlysimeter station 1 for long term non-rainfall water input and evaporation studies" by Uclés et al. Agric. For. Meteorol. 194, 255-256.

Ait Hssaine, B., Merlin, O., Rafi, Z., Ezzahar, J., Jarlan, L., Khabba, S., Er-Raki, S., 2018. Calibrating an evapotranspiration model using radiometric surface temperature, vegetation cover fraction and near-surface soil moisture data. Agric. For. Meteorol. 256-257, 104-115.

Allen, R. G., Pereira, L. S., Raes, D., Smith, M., 1998. Crop evapotranspiration - Guidelines for computing crop water requirements. FAO irrigation and drainage paper 56.

Allen, R.G., 2000. Using the FAO-56 dual crop coefficient method over an irrigated region as part of an evapotranspiration intercomparison study. J. Hydrol. 229(1), 27-41.

Allen, R.G., Pereira, L.S., Howell, T.A., Jensen, M.E., 2011. Evapotranspiration information reporting: I. Factors governing measurement accuracy. Agric. Water Manage. 98, 899-920.

Anderson, R. G., Alfieri, J. G., Tirado-Corbalá, R., Gartung, J., McKee, L. G., Prueger, J. H., Wang, D., Ayars, J. E., Kustas W. P., 2017. Assessing FAO-56 dual crop coefficients using eddy covariance flux partitioning. Agric. Water Manage. 179, 92-102

Aouade, G., Ezzahar, J., Amenzou, N., Er-Raki, S., Benkaddour, A., Khabba, S., Jarlan, L., 2016. Combining stable isotopes, Eddy Covariance system and meteorological measurements for partitioning evapotranspiration, of winter wheat, into soil evaporation and plant transpiration in a semi-arid region. Agric. Water Manage. 177, 181-192.

Baldocchi, D.D., Xu, L., Kiang, N., 2004. How plant functional-type, weather, seasonal drought, and soil physical properties alter water and energy fluxes of an oak-grass savanna and an annual grassland. Agric. For. Meteorol. 123, 13-39.

Balwinder-Singh, Eberbach, P.L., Humphreys, E., Kukal, S.S., 2011. The effect of rice straw mulch on evapotranspiration, transpiration and soil evaporation of irrigated wheat in Punjab, India. Agric. Water Manage. 98(12), 1847-1855.

Belaqziz, S., Khabba, S., Er-Raki, S., Jarlan, L., Le Page, M., Kharrou, M.H., El Adnani, M., Chehbouni, G. 2013. A new Irrigation Priority Index based on remote sensing data for assessing the networks irrigation scheduling. Agric. Water Manage. 119, 1-9. 
Boast, C.W., Robertson, T.M., 1982. A "micro-lysimeter" method for determining evaporation from bare soil: description and laboratory evaluation. Soil Sci. Soc. Am. J. 46(4), 689-696.

Boone, A., Samuelsson, P., Gollvik, S., Napoly, A., Jarlan, L., Brun, E., Decharme B., 2017. The interactions between soil-biosphere-atmosphere land surface model with a multi-energy balance (ISBA-MEB) option inSURFEXv8 - Part 1: Model description. Geosci. Model Dev., $10,843-872$.

Brye, K.R., Norman, J.M., Bundy, L.G., Gower, S.T., 1999. An equilibrium tension lysimeter for measuring drainage through soil. Soil Sci. Soc. Am. J. 63(3), 536-543.

Cammalleri, C., Rallo, G., Agnese, C., Ciraolo, G., Minacapilli, M., Provenzano, G., 2013. Combined use of eddy covariance and sap flow techniques for partition of ET fluxes and water stress assessment in an irrigated olive orchard. Agric. Water Manage. 120, 89-97.

Chanzy, A., Mumen, M., and Richard, G. (2008). Accuracy of top soil moisture simulation using a mechanistic model with limited soil characterization, Water Resour. Res. 44, W03432.

Cooper, P.J.M., Keatinge, J.D.H., Hughes, G., 1983. Crop evapotranspiration-a technique for calculation of its components by field measurements. Field Crops Research. 7, 299-312.

Daamen, C.C., Simmonds, L.P., Wallace, J.S., Laryea, K.B., Sivakumar, M.V.K., 1993. Use of microlysimeters to measure evaporation from sandy soils. Agric. For. Meteorol. 65(3-4), 159-173.

Denmead, O.T., Dunin, F.X., Leuning, R., Raupach, M.R., 1996. Measuring and modelling soil evaporation in wheat crops. Phys. Chem. Earth. 21(3), 97-100.

Ding R., Kang S., Zhang Y., Hao,X., Tong L., Du T., 2013. Partitioning evapotranspiration into soil evaporation and transpiration using a modified dual crop coefficient model in irrigated maize field with ground-mulching. Agric. Water Manage. 127, 85-96.

Drusch M., Moreno J., Del Bello U., Franco R., Goulas Y., Huth A., Kraft S., Middleton E. M., Miglietta F., Mohammed G., Nedbal L., Rascher U., Schüttemeyer D., Verhoef W., 2017. The FLuorescence EXplorer Mission Concept—ESA's Earth Explorer 8. IEEE Trans. Geosci. Remote Sens. 55(3).

Dynamax Inc, 2005. Dynagage Sap Flow Sensor: User manual. Dynamax, Houston, TX, USA.

Er-Raki, S., Chehbouni, A., Guemouria, N., Duchemin, B., Ezzahar, J., Hadria R., 2007. Combining FAO-56 model and glound-based remote sensing to estimate water consumptions of wheat crops in a semi-arid region. Agric. Water Manage. 87, 41-54.

Er-Raki, S., Chehbouni, A., Ezzahar, J., Khabba, S., Lakhal, E.K. Duchemin, B., 2011. Derived crop coefficient for winter wheat using different reference evpotranspiration estimates methods. Journal of Agricultural Science and Technology, 13, 209-221. 
Er-Raki, S., Khabba, S., Er-raji, T., Ezzahar, J., Jarlan, L., Hanich, L., Chehbouni A., 2012. Evaluation of the sap flow measurements determined with Heat Balance Method for citrus orchards in semi-arid region. Acta Hortic. 951, 259-268.

Ferreira, M.I., Silvestre, J., Conceição, N., Malheiro, A.C., 2012. Crop and stress coefficients in rainfed and deficit irrigation vineyards using sap flow techniques. Irrigation science, 30(5), 433-447.

Van Halsema, G. E., Vincent, L., 2012. Efficiency and productivity terms for water management: A matter of contextual relativism versus general absolutism. Agric. Water Manage. 108(C), 9-15.

Gerdes, G., Allison, B.E., Pereira, L.S., 1994. Overestimation of soybean crop transpiration by sap flow measurements under field conditions in Central Portugal. Irrigation Science, 14(3), 135-139.

Gharsallah, O., Facchi, A., Gandolfi, C., 2013. Comparison of six evapotranspiration models for a surface irrigated maize agro-ecosystem in Northern Italy. Agric. Water Manage. 130, 119- 130

Grimmond, C.S.B., Isard, S.A., Belding, M.J., 1992. Development and evaluation of continuously weighing mini-lysimeters. Agric. For. Meteorol. 62(3-4), 205-218.

Heilman, Ham, J.M., 1990. Measurement of mass flow rate of sap in Ligustrum japonicum. HortScience, 25(4), 465-467.

Jarlan, L., Khabba, S., Er-Raki, S., Le Page, M., Hanich, L., Fakir, Y., Merlin, O., Mangiarotti, S., Gascoin, S., Ezzahar, J., Kharrou, M.H., Berjamy, B., Saaïdi, A., Boudhar, A., Benkaddour, A., Laftouhi, N., Abaoui, A., Tavernier, A., Boulet, G., Simonneaux, V., Driouech, F., El Adnani, M., El Fazziki, A., Amenzou, A., Raibi, F., El Mandour, A., Ibouh, H., Le Dantec, V., Habets, F., Tramblay, Y., Mougenot, B., Leblanc, M., El Faïz, M., Drapeau, L., Coudert, B., Hagolle, O., Filali, N., Belaqziz, S., Marchane, A., Szczypta, C., Toumi, J., Diarra, A., Aouade, G., Hajhouji, Y., Nassah, H., Bigeard, G., Chirouze, J., Boukhari, K., Abourida, A., Richard, B., Fanise, P., Kasbani, M., Chakir, A., Zribi, M., Marah, H., Naimi, A., Mokssit, A., Kerr, Y., Escadafal, R., 2015. Remote Sensing of Water Resources in the semi-arid Mediterranean areas: The Joint International Laboratory TREMA. Int. J. Remote Sens. 36 (19-20), 4879-4917.

Merlin, O., Stefan, V. G., Amazirh, A., Chanzy, A., Ceschia, E., Er-Raki, S., Gentine, P., Tallec, T., Ezzahar, J., Bircher, S., Beringer, J., Khabba, S., 2016. Modeling soil evaporation efficiency in a range of soil and atmospheric conditions using a meta-analysis approach. Water Resour. Res. 52 (5), 3663-3684.

Moore, C.J., 1986. Frequency response corrections for eddy correlation systems. Boundary Layer Meteorol. 37, 17-35. 
Moreno, J., Colombo, R., Damm, A., Goulas, Y., Middleton, E., Miglietta, F., Mohammed, G., Möttus, M., North, P., Rascher, U., Van der Tol, C., Drusch, M., 2017. Quantitative global mapping of terrestrial vegetation photosynthesis: The Fluorescence Explorer (FLEX) Mission. IGARSS 2017 (IEEE Geosci. Remote Sens. Lett.), Fort Worth, Texas, USA, July, 23-28.

Kang, S., Gu, B., Du, T., Zhang, J., 2003. Crop coefficient and ratio of transpiration to evapotranspiration of winter wheat and maize in a semi-humid region. Agric. Water Manage. 59(3), 239-254.

Kool, D., Agam, N., Lazarovitch, N., Heitman, J.L., Sauer, T.J., Ben-Gal, A., 2014. A review of approaches for evapotranspiration partitioning. Agric. For. Meteorol. 184, 56-70.

Le Page, M., Toumi, J., Khabba, S., Hagolle, O., Tavernier, A., Kharrou, H., Er-Raki, S., Huc, M., Kasbani, M., El Moutamanni, A., Yousfi, M., Jarlan, L., 2014. A Life-Size and Near Real-Time Test of Irrigation Scheduling with a Sentinel-2 Like Time Series (SPOT4-Take5) in Morocco. Remote Sens. 6(11), 11182-11203.

Leuning, R., Condon, A.G., Dunin, F.X., Zegelin, S., Denmead, O.T., 1994. Rainfall interception and evaporation from soil below a wheat canopy. Agric. For. Meteorol. 67(3-4), 221-238.

Liu, C., Zhang, X., Zhang, Y., 2002. Determination of daily evaporation and evapotranspiration of winter wheat and maize by large-scale weighing lysimeter and microlysimeter. Agric. For. Meteorol. 111(2), 109-120.

Liu, Y., Luo, Y., 2010. A consolidated evaluation of the FAO-56 dual crop coefficient approach using the lysimeter data in the North China Plain. Agric. Water Manage. 97(1), 3140.

Merlin, O., Stefan, V.G., Amazirh, A., Chanzy, A, Ceschia, E., Er-Raki, S., Gentine, P., Tallec, T., Ezzahar, J., Bircher, S., Beringer, J., and Khabba, S., 2016. Modeling soil evaporation efficiency in a range of soil and atmospheric conditions using a meta-analysis approach, Water Resources Research, 52, 5, 3663-3684.

Merlin, O., Olivera-Guerra, L., Ait Hssaine, B., Amazirh, A., Rafi, Z., Ezzahar, J., Gentine, P., Khabba, S., Gascoin S., and Er-Raki, S., 2018. A phenomenological model of soil evaporative efficiency using surface soil moisture and temperature data. Agricultural and Forest Meteorology, 256, 501-515.

PMV (Plan Maroc Vert), 2013. Plan Maroc Vert: Région de Marrakech Tensift Al Haouz. Rabat. http://www.agriculture.gov.ma/sites/default/files/sam_fr_10.pdf.

Pruitt, W.O., Lourence, F.J., 1985. Experiences in lysimetry for ET and surface drag measurements. In: Advances in Evapotranspiration. Am. Soc. of Agr. Engrs., St. Joseph, MI, USA, 51-69.

Saadi, S., Simonneaux, V., Boulet, G., Raimbault, B., Mougenot, B., Fanise, P., Ayari, H., Lili-Chabaane, Z., 2015. Monitoring irrigation consumption using high-resolution NDVI 
image time series: calibration and validation in the Kairouan plain (Tunisia). Remote Sens. 7(10), 13005-13028.

Scott, R.W.C., Garatuza-Payan, J., Edwards, E., Goodrich, D.C., Williams, D.G., Shuttleworth, W.J., 2003. The understory and overstory partitioning of energy and water fluxes in an open canopy, semi-arid woodland. Agric. For. Meteorol. 114, 127-139.

Senock, R., Ham, J., 1993. Heat balance sap flow gauge for small diameter stems. Plant, Cell and Environment, (16), 593-601.

Smith, D.M., Allen, S.J., 1996. Measurement of sap flow in plant stems. J. Exp. Bot. 47(305), 1833-1844.

Testi, L., Villalobos, F.J., Orgaz, F., 2004. Evapotranspiration of a young irrigated olive orchard in southern Spain. Agric. For. Meteorol. 121, 1-18.

Thompson, A.L., Martin, D.L., Norman, J.M., Tolk, J.A., Gilley, J.R., Schneider, A.D., 1997.Testing of a water loss distribution model for moving sprinkler systems. Trans.ASAE 40, 81-88.

Twine, T.E., Kustas, W.P., Norman, J.M., Cook, D.R., Houser, P.R., Meyers, T.P., Prueger, J.H., Starks, P.J., Wesely, M.L., 2000. Correcting eddy-covariance flux underestimates over a grassland. Agric. For. Meteorol. 103, 279-300.

Uclés, O., Villagarcía, L., Cantón, Y., Domingo, F., 2013. Microlysimeter station for long term non-rainfall water input and evaporation studies. Agric. For. Meteorol. 182, 13-20.

Van Dijk, A., Moene, A.F. De Bruin, H.A.R., 2004. The principles of surface flux physics: theory, practice and description of the ECPACK library. Internal Report 2004/1, Meteorology and Air Quality Group, Wageningen University, Wageningen, The Netherlands, 99 pp.

Williams, D.G., Cable, W., Hultine, K., Hoedjes, J.C.B., Yepez, E.A., Simonneaux, V., ErRaki, S., Boulet, G., De Bruin, H.A.R., Chehbouni, A., Hartogensis, O.K., 2004. Evapotranspiration components determined by stable isotope, sap flow and eddy covariance techniques. Agric. For. Meteorol. 125(3), 241-258.

Zhang, Y., Shen, Y., Sun, H., Gates, J.B., 2011. Evapotranspiration and its partitioning in an irrigated winter wheat field: A combined isotopic and micrometeorologic approach. J. Hydrol. 408(3), 203-211.

Zhang, Y., Liu, C., Shen, Y., Kondoh, A., Tang, C., Tanaka, T., Shimada, J., 2002. Measurement of evapotranspiration in a winter wheat field. Hydrol. Processes, 16(14), 28052817.

\section{Appendix A:}


The SFL system is fully automated and provides continuous measurements of precipitation (P) or irrigation during rainfall/irrigation events and ET at any other time. In addition, it measures the water drainage (D) at the Lys bottom, which makes it possible to determine the refilling capacity of groundwater at a certain depth of soil. The determination of the water balance components is based on the variations of the weight of: 1) the soil column in the Lys and 2) a drainage bottle connected to the Lys bottom. The SFL scales provide weight data at the 1 min time step. Another special feature of the SFL system is that each Lys is tensioncontrolled, meaning that the soil water tension inside the Lys is regulated by pumping in or pumping out water at the Lys bottom so as to closely follow the soil water tension measured in real field conditions (outside the Lys) at the same depth. Therefore, the system continuously ensures that the Lys bottom boundary conditions are representative of field conditions at the same depth.

ET and rainfall/irrigation are estimated as the residual term of the water balance. Note that the lysimetric measurement principle cannot estimate both input and output terms simultaneously during the elementary measurement period (defined as the period between two weight measurements). The $\mathrm{P}$ calculation is based on the assumption that during the elementary period (set to $10 \mathrm{~min}$ in our case), $\mathrm{P}$ is much larger than ET so that ET is negligible. Therefore, ET is set to zero during rainfall/irrigation events:

$$
P_{L Y S}=\Delta S_{L Y S}+D_{L Y S}
$$

with $\mathrm{P}_{\mathrm{LYS}}(\mathrm{mm} / 10 \mathrm{~min})$ being the confounded volumes of rainfall and irrigation and $\Delta \mathrm{S}_{\mathrm{LYS}}$ $(\mathrm{mm} / 10 \mathrm{~min})$ the variation of the water volume stored in the Lys calculated over a period of $10 \mathrm{~min}$. The storage term is estimated as:

$$
\Delta S_{L Y S}=\left[\left(L_{m}(t)-L_{m}(t-10)\right] * 14.15\right.
$$

where $\mathrm{L}_{\mathrm{m}}(\mathrm{t})(\mathrm{kg})$ is the weight of the soil column in the Lys at time $\mathrm{t}$ [min], and the coefficient 14.15 corresponds to the conversion factor used to convert weight differences into $\mathrm{mm}$ of water per $\mathrm{m}^{2}$ of surface area. In fact, the disk surface of the SFL Lys is $0.0707 \mathrm{~m}^{2}$, so that a 1 $\mathrm{kg}$ change in mass corresponds to $14.15 \mathrm{~mm}$ of water per $\mathrm{m}^{2}$. Similarly, the D term is estimated as:

$$
D_{L Y S}=\left[S_{m}(t)-S_{m}(t-10)\right] * 14.15
$$

where $S_{m}(t)(\mathrm{kg})$ is the weight of the $\mathrm{D}$ bottle at time $\mathrm{t}(\mathrm{min})$. To reduce random uncertainties in $S_{m}$ and $L_{m}$ measurements, the average of 3 successive (1-min) measurements around time $t$ is taken for the computation of $\mathrm{D}_{\mathrm{LYS}}$ and $\Delta \mathrm{S}_{\mathrm{LYS}}$, respectively. The daily fluxes (mm/day) are finally obtained by summing up the 10-min estimates derived in Equations (1-3).

For days when there is no irrigation/rainfall, ET is estimated as:

$$
E T_{L Y S}=-\Delta S_{L Y S}-D_{L Y S}
$$


where $\mathrm{ET}_{\mathrm{LYS}}\left(\mathrm{mm} /\right.$ day) is the daily $\mathrm{ET}, \Delta S_{L Y S}(\mathrm{~mm} /$ day) the variation of the water volume stored in the Lys and $D_{L Y S}\left(\mathrm{~mm} /\right.$ day) the daily drainage. The $\Delta S_{L Y S}$ and $D_{L Y S}$ of Equation (4) are calculated over a period of 1 day:

$$
\begin{aligned}
& \Delta S_{L Y S}=\left[L_{m}(t)-L_{m}(t-24 * 60)\right] * 14.15 \\
& D_{L Y S}=\left[S_{m}(t)-S_{m}(t-24 * 60)\right] * 14.15
\end{aligned}
$$

To reduce random uncertainties in $\mathrm{L}_{\mathrm{m}}$ and $\mathrm{S}_{\mathrm{m}}$ and measurements in Equations (A5) and (A6), respectively, the average of 15 successive (1-min) measurements around time t (midnight) is taken for the computation daily fluxes.

For days when an irrigation episode occurs, the weight generated by irrigation water is subtracted to the daily ET estimated in Equation (4). In practice, the variation of the Lys weight is expressed as:

$$
\Delta S_{L Y S}=\Delta S_{L Y S, 1}+\Delta S_{L Y S, 2}
$$

with $\Delta S_{L Y S, 1}$ and $\Delta S_{L Y S, 2}$ being the storage variations associated with the ET outside the irrigation period and the ET during the irrigation period, respectively. The first term of Equation (7) is computed as:

$$
\Delta S_{L Y S, 1}=\left\{\left[L_{m}(t)-L_{m}(t-24 * 60)\right]-\left[L_{m}\left(t_{E I}\right)-L_{m}\left(t_{S I}\right)\right]\right\} * 14.15
$$

where $t_{\mathrm{SI}}$ and $\mathrm{t}_{\mathrm{EI}}$ are the start and end time of irrigation, respectively. The second term is computed as:

$$
\Delta S_{L Y S, 2}=\left(t_{E I}-t_{S I}\right) * Q_{d}-\left[L_{m}\left(t_{E I}\right)-L_{m}\left(t_{S I}\right)\right] * 14.15
$$

where $\mathrm{Q}_{\mathrm{d}}$ is the hourly flow rate of the dripper at the Lys level.

For days when a rainfall episode occurs, daily ET is estimated in the same way as for irrigation days, except that the $\Delta S_{L Y S, 2}$ term in Equation (7) is set to zero. It is thus assumed that the ET during rainfall events is negligible compared to the daily ET due to a lower potential evaporative demand in the presence of clouds.

\section{Appendix B:}

SHB sensors are composed of a heating resistor, a thermopile and two thermocouples on either side of the resistor. The heating resistor is applied around the stem with the thermocouples. Insulation is added all around the devices to avoid any external thermal bias. It can therefore be considered that the only heat energy received by the section of the stem comes from the heating resistor, denoted $\mathrm{P}_{\text {in }}$ and expressed in $\mathrm{W}$ unit (Smith \& Allen, 1996).

The energy $\mathrm{P}_{\text {in }}$ received by the stem is divided into four diffusion factors:

$$
P_{\text {in }}=q_{v}+q_{r}+q_{f}+q_{s}
$$


with $\mathrm{q}_{v}$ corresponding to the energy diffused vertically in the stem by conduction, $\mathrm{q}_{\mathrm{r}}$ the radial energy lost by conduction, $\mathrm{q}_{\mathrm{f}}$ the energy diffused via the $\mathrm{SF}$ by convection, and $\mathrm{q}_{\mathrm{s}}$ the change rate of the heat storage.

Considering that the conditions of the system are stationary, $\mathrm{q}_{\mathrm{s}}$ is often ignored. Senock and Ham (1993) investigated the effect of this parameter on the flux calculation for a soybean stem and found that $\mathrm{q}_{\mathrm{s}}$ accounts for only $3 \%$ of the total daily thermal flux. In this case, $\mathrm{q}_{\mathrm{s}}$ had no significant effect on the estimated SF.

Once all the fluxes $\left(\mathrm{P}_{\mathrm{in}}, \mathrm{q}_{\mathrm{v}}\right.$ and $\mathrm{q}_{\mathrm{r}}$ ) are determined, the intensity of the sap flux $\mathrm{F}$ (g/hour) can be calculated as:

$$
\mathrm{F}=\frac{P_{i n}-q_{v}-q_{r}}{C_{e^{*}} d T}
$$

where $\mathrm{C}_{\mathrm{e}}\left(\mathrm{J}_{\mathrm{g}} \mathrm{g}^{-1} \cdot{ }^{\circ} \mathrm{C}^{-1}\right)$ is the specific heat of water and $\mathrm{dT}\left({ }^{\circ} \mathrm{C}\right)$ the sap temperature difference between the base and the top of the heating element. As the flux calculated in Equation (B2) is representative of a single stem, an upscaling strategy is needed to extrapolate this result at the $1 \mathrm{~m}^{2}$ scale:

$$
T_{S F}=\frac{\left(F * N_{S t}\right)}{1000}
$$

where $\mathrm{T}_{\mathrm{SF}}(\mathrm{mm} /$ hour $)$ is the SF-derived $\mathrm{T}$ and $\mathrm{N}_{\mathrm{st}}$ the number of stems per $\mathrm{m}^{2}$.

\section{Appendix C:}

The main equations of the FAO-2Kc approach are briefly reminded below. For more details, please refer to the FAO-56 documentation (Allen et al., 1998) and related published work (e.g. Er-Raki et al., 2007, Le Page et al., 2014).

In the FAO-2Kc approach, the evolution of $\mathrm{K}_{\mathrm{cb}}$ is subdivided into four growth phases. At beginning of the culture, the plant emerges and is created during the initial phase $\left(l_{\text {ini }}\right)$. Then the plant experiences a rapid increase during the so-called development phase $\left(l_{\mathrm{dev}}\right)$. Later, the development reaches its maximum during the mid-season phase $\left(1_{\mathrm{mid}}\right)$. Finally, the senescence occurs during the end-of-season phase $\left(l_{\text {late }}\right)$, which lasts until harvest. The $\mathrm{K}_{\mathrm{cb}}$ parameter is thus decomposed into $\mathrm{K}_{\mathrm{cb} \text {,ini }}, \mathrm{K}_{\mathrm{cb} \text {,dev }}, \mathrm{K}_{\mathrm{cb} \text {,mid }}$ and $\mathrm{K}_{\mathrm{cb} \text {,end }}$ for the initial, development, mid-season and end-of-season periods, respectively. The $\mathrm{K}_{\mathrm{cb}}$ was interpolated during the growth phase as in the FAO-56 documentation. In practice, the $\mathrm{K}_{\mathrm{cbmid}-\text { season }}$ was linearly interpolated using the initial $\mathrm{K}_{\mathrm{cb}}$. Lengths of growth stages $\left(1_{\mathrm{ini}}, 1_{\mathrm{dev}}, 1_{\mathrm{mid}}, 1_{\text {late }}\right.$ ) are usually calculated based on the fractional vegetation cover fc.

The E coefficient $\mathrm{K}_{\mathrm{e}}$ is calculated as:

$$
K_{e}=\min \left(K_{r} *\left(K_{c, \max }-K_{c b}\right), f_{e w} * K_{c, \max }\right)
$$


where $\mathrm{K}_{\mathrm{c} \text {,max }}$ is the maximum value of $\mathrm{K}_{\mathrm{c}}$ following rain or irrigation, $\mathrm{K}_{\mathrm{r}}$ is the dimensionless $\mathrm{E}$ reduction coefficient dependent on the cumulative depth of water depleted (evaporated) from the topsoil and $f_{e w}$ is the fraction of the soil that is both exposed and wetted. The $K_{e}$ coefficient changes rapidly to a maximum value after a precipitation or irrigation event, and then decreases to zero when the soil surface dries out with very little or no E. The calculation of this coefficient requires a daily water balance for the soil surface layer with an effective depth $Z_{e}$. The calculation procedure requires input soil parameters such as the soil moisture at field capacity $\left(\Theta_{\mathrm{fc}}\right)$ and at the wilting point $\left(\Theta_{\mathrm{wp}}\right)$, the readily evaporable water (REW), and the depth of $\mathrm{Z}_{\mathrm{e}}$.

The determination of $\mathrm{K}_{\mathrm{s}}$ requires a daily calculation of the water balance for the root zone (with depth $\mathrm{Z}_{\mathrm{r}}$ ). The water supply in the root zone is reflected through the root zone depletion $\left(D_{r}\right)$. At $\Theta_{\text {fc }}, D_{r}$ is zero and $K_{s}=1$ (no stress). Water stress occurs when the $D_{r}$ becomes greater than the depth of readily available water (RAW) in the root zone. For $D_{r}>R A W, K_{s}$ is given by Allen et al. (1998):

where $\mathrm{p}$ is the fraction of TAW (total available water) that a crop can extract from the root zone under no water stress conditions. TAW is derived from $Z_{r}, \theta_{\text {fc }}$ and $\Theta_{w p}$. The recommended $\mathrm{p}$ value for winter wheat is 0.55 when $\mathrm{ET}_{\mathrm{c}}$ is $5 \mathrm{~mm} /$ day (FAO-56, Table 22). When $\mathrm{ET}_{\mathrm{c}}$ differs from $5 \mathrm{~mm} /$ day, $\mathrm{p}$ can be adjusted using the following approximation:

$$
p=0.55+0.04 *\left(5-E T_{c}\right)
$$

